\title{
REopt: Energy Decision Analysis
}

\author{
NREL REopt Team \\ reopt.nrel.gov
}

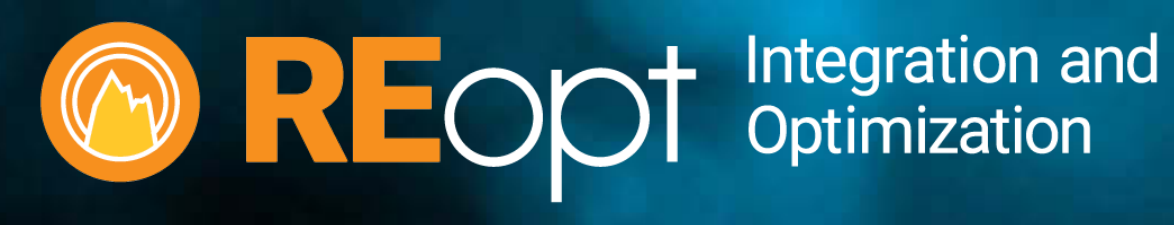






\section{REopt Energy Planning Platform}

Formulated as a mixed integer linear program, REopt provides an integrated, cost-optimal energy solution.

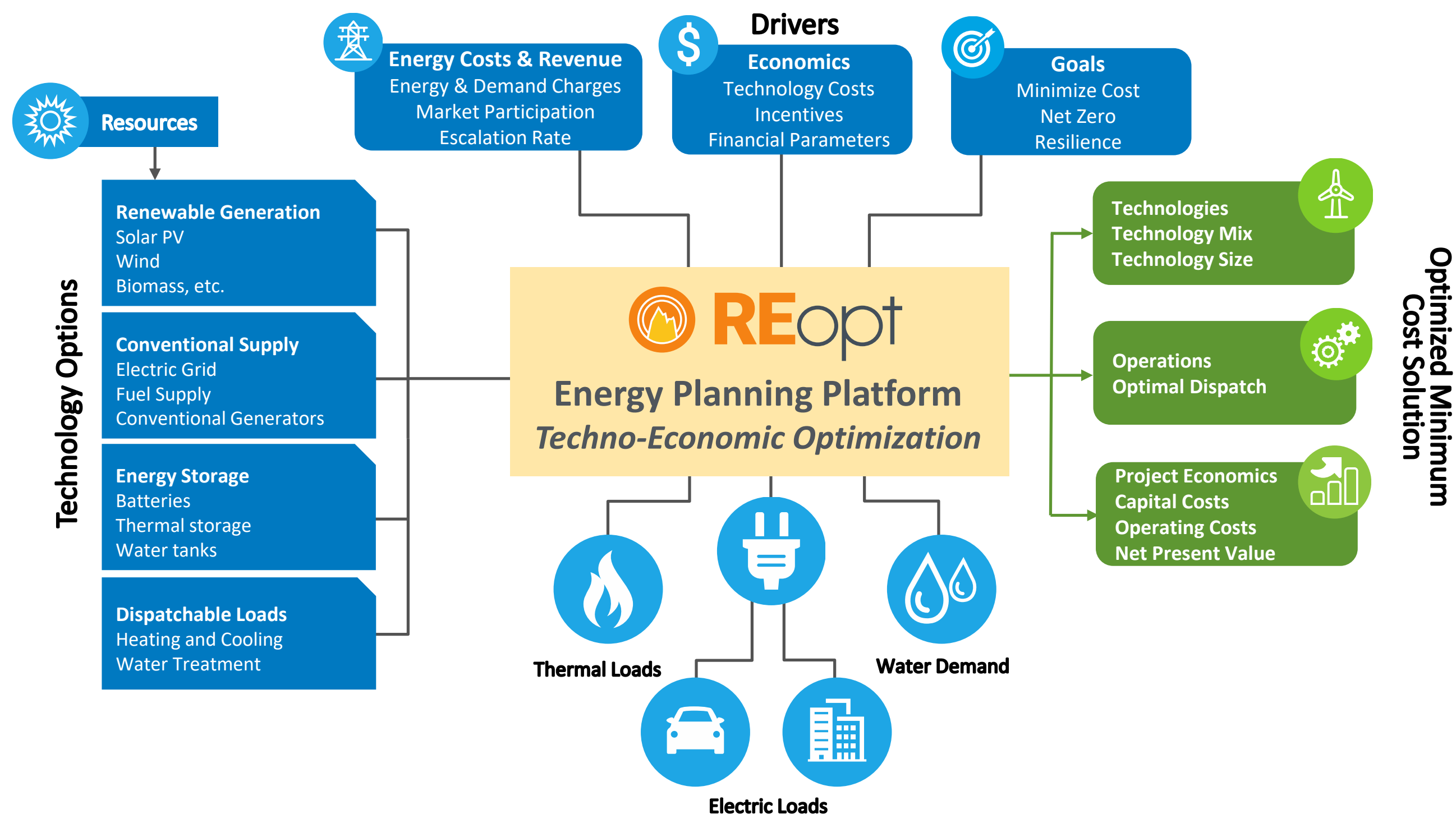




\section{REopt Provides Solutions for a Range of Users}

\section{Including researchers, developers, building owners, utilities, and industry}

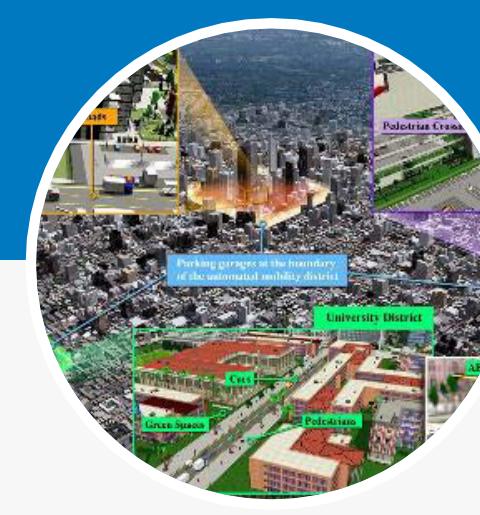

What is the optimal size of distributed energy resources (DERs) to minimize my cost of energy?

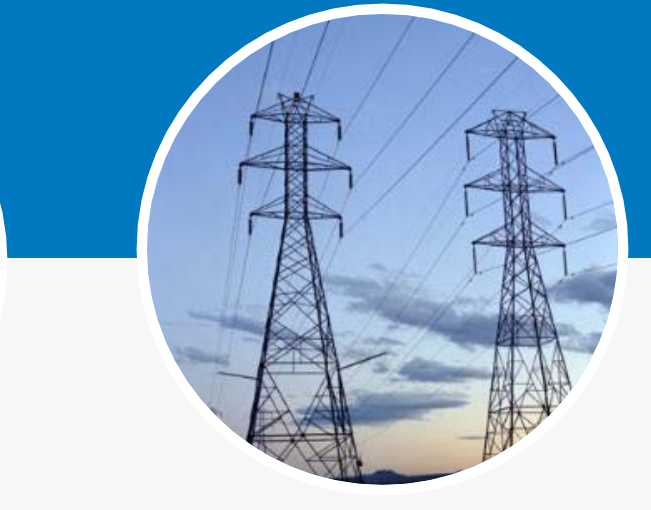

How do I optimize system control across multiple value streams to maximize project value?

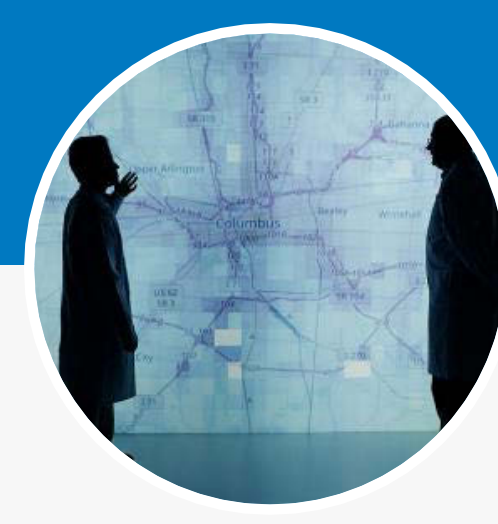

Where do market opportunities for DERs exist? Now and in the future?

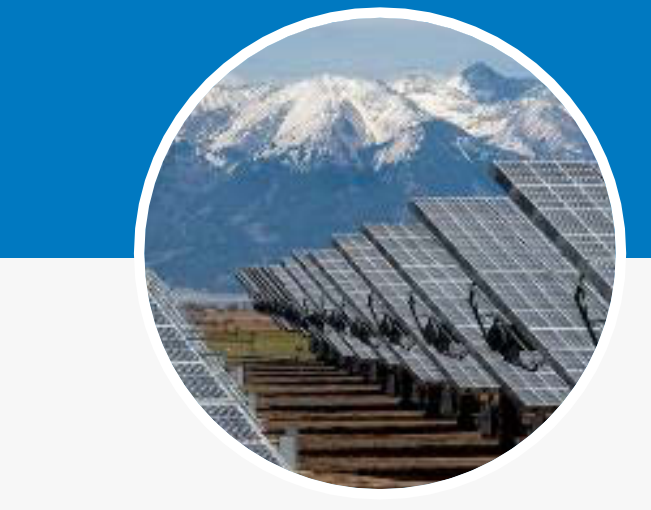

What will it cost to meet my sustainability or resilience goal?

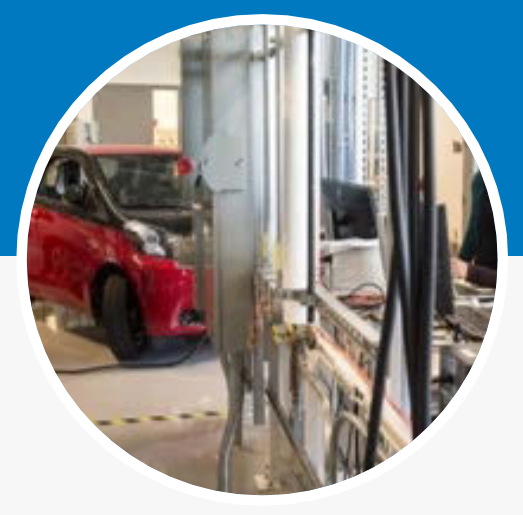

What is the most costeffective way for me to survive a grid outage? 


\section{How Does REopt Work?}

REopt considers the trade-off between ownership costs and savings across multiple value streams to recommend optimal size and dispatch.

\section{Demand Reduction}

Setting peak for the month
Energy Arbitrage

Buy cheap, use high

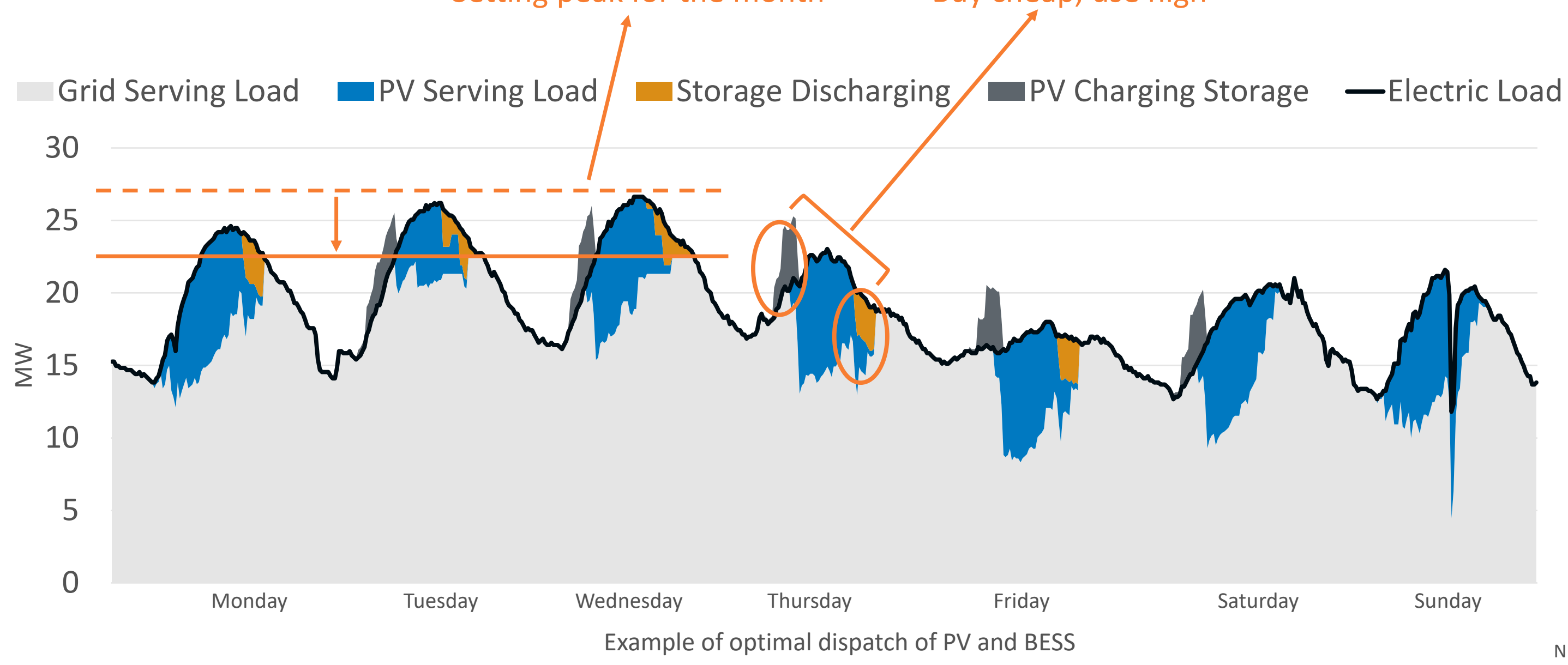




\section{How Does REopt Evaluate Resilience?}

REopt finds the system size and dispatch that minimizes life cycle energy costs for grid-connected operations and survives a specified grid outage. It evaluates thousands of random grid outage occurrences and durations to identify the probability of survival.

Existing generator with fixed fuel supply sustains the critical load for 5 days with $90 \%$ probability
Adding solar and storage to the existing generator increases survivability from 5 to 9 days by extending fixed diesel fuel supplies and provides utility cost savings while grid-connected.

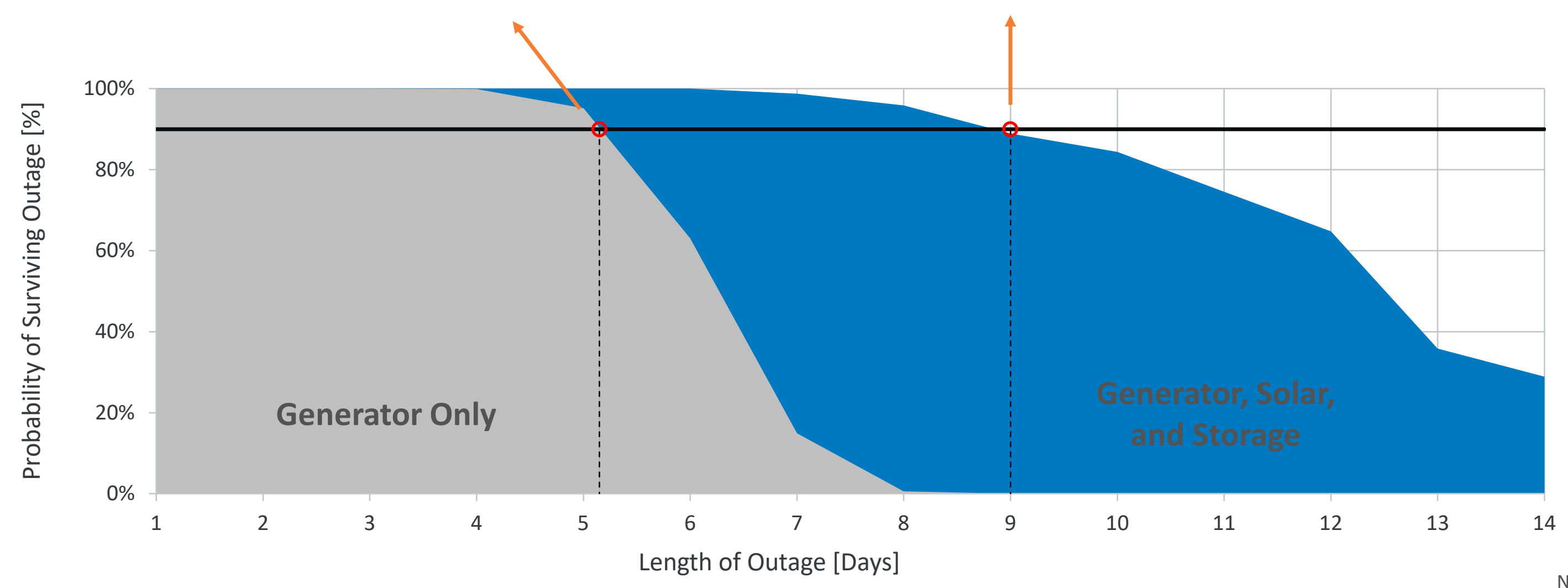




\section{Optimal Sizing and Dispatch at Single Site}

- REopt helps partners make well-informed energy investment decisions backed by credible, objective data analysis.

- Typical questions from clients include:

- How should RE and storage be sized and dispatched to minimize site energy costs?

- What is the value (or net present value) of a project?

- How should I dispatch my battery to maximize the value across multiple value streams? During an outage?

- What technologies will sustain my critical load during an outage at lowest cost?

- What is the optimal mix and size of technologies to meet a renewable energy goal? How much will it cost?

- How can dispatchable loads, such as smart domestic water heaters, air conditioners, water purification and treatment, electric vehicles, and storage, be used to maximize the value of RE and provide grid services?

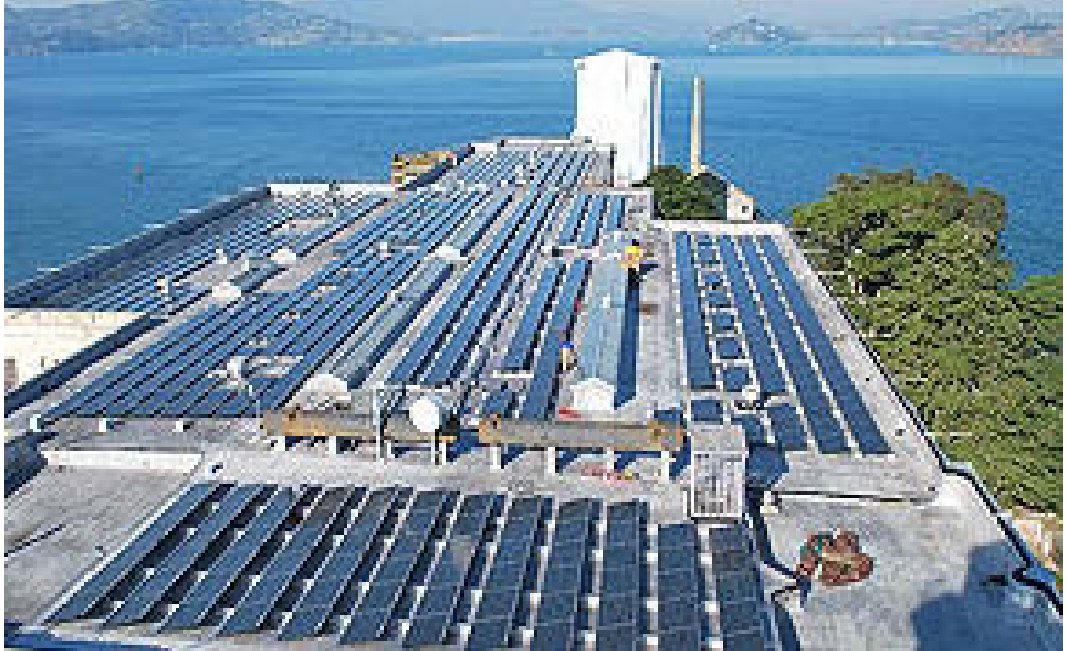

Alcatraz PV-battery-diesel hybrid system completed in 2012. NREL provided technical assistance to optimize the dispatch.

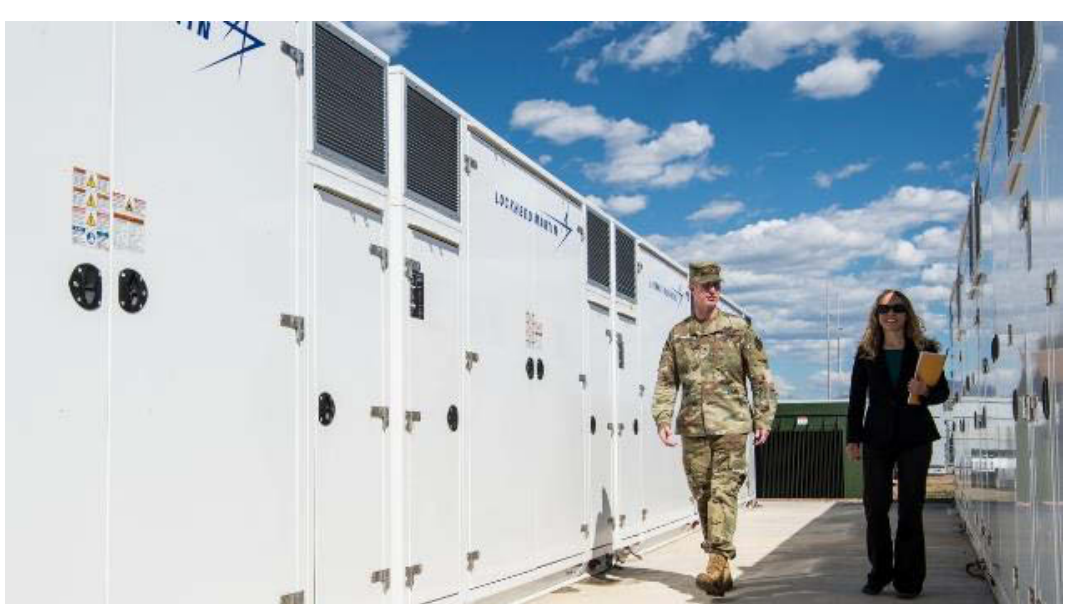

Ft. Carson 4.25 MW/8.5 MWh peak-shaving Li-ion BESS completed in 2019. NREL provided technical assistance to validate the $\$ 0.5$ million/year savings. 


\section{Project Economics at National Scale}

- REopt enables national-scale analysis of renewable energy (RE) and storage economics and impacts on deployment

- Analysis questions include:

- Where in the country is storage and photovoltaics (PV) currently cost-effective?

- At what capital cost is storage adopted across the United States?

- Under what conditions (utility rate, load profile, location) can RE and storage provide cost savings and resilience benefits for commercial buildings?

- How do varying utility rates, projected costs, and incentive structures impact storage profitability?

- How do I prioritize projects across a portfolio of sites with varying energy costs and use, renewable energy resources, and land availability?

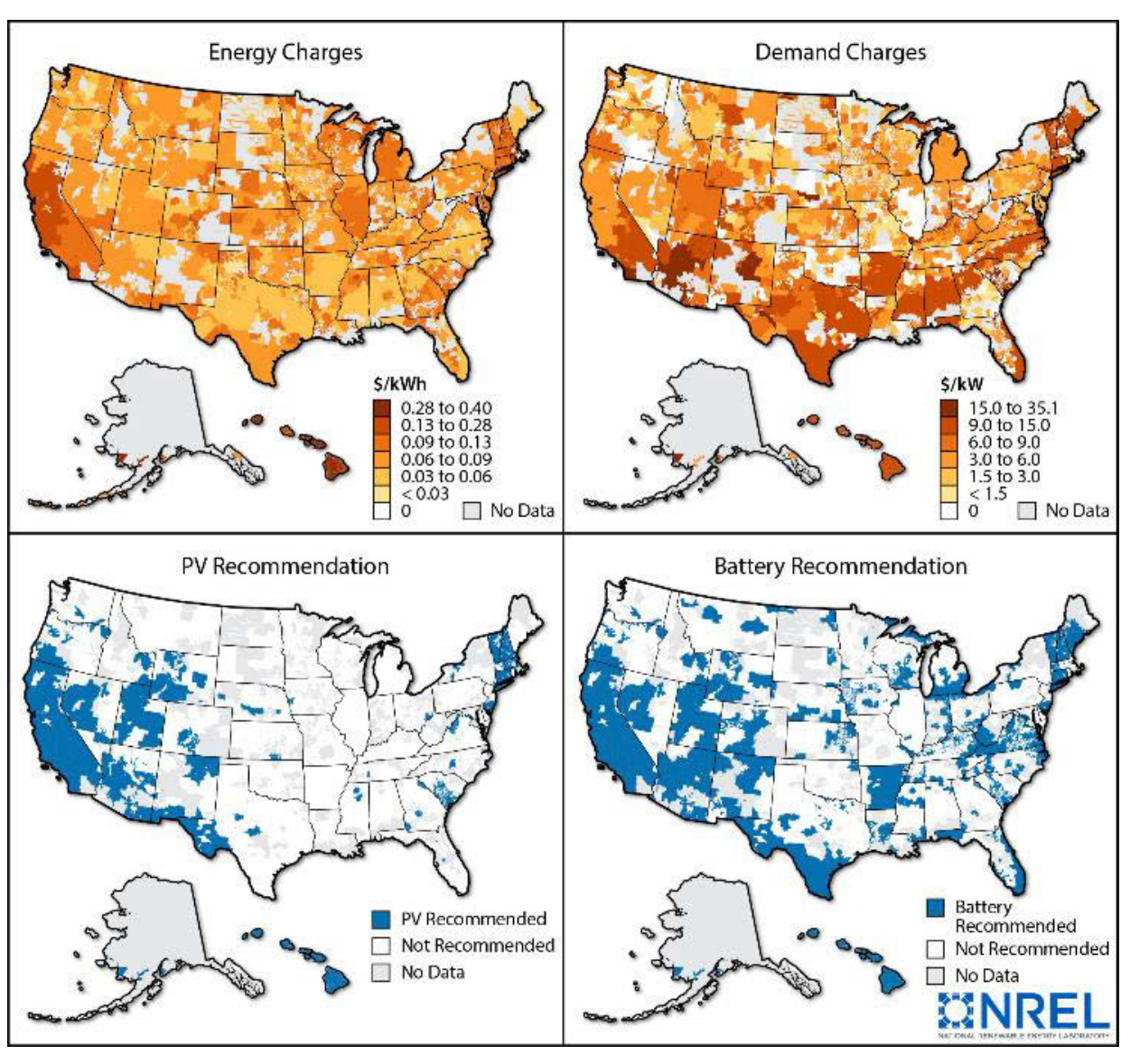

NREL explored solutions for increasing affordability of $D C$ fast charging (DCFC) nationwide through pairing with solar, storage, and building loads. 


\section{Accessing REopt}

The REopt team provides a suite of trusted techno-economic decision support services and software to optimize energy systems for buildings, campuses, communities, microgrids, and more.

The team also develops the publicly available REopt Lite tool, which contains a subset of REopt's features. Capabilities developed in REopt are transferred to REopt Lite based on broad use and validation, customer needs, and funding available.

\section{REopt Decision Support Services}

Allows organizations to work closely with

NREL's team of experts on customized analysis, answering complex energy questions using an expanded set of internal modeling capabilities.

\section{REopt Lite ${ }^{\mathrm{TM}}$ Software}

Developed by the REopt team, the tool guides users to the most cost-effective or resilient PV, wind, and battery storage options at no cost to users. Available via web tool, application programming interface (API), and open source. 
REopt Projects and Successes 


\section{Field Validation of Utility-Scale Storage Value Streams}

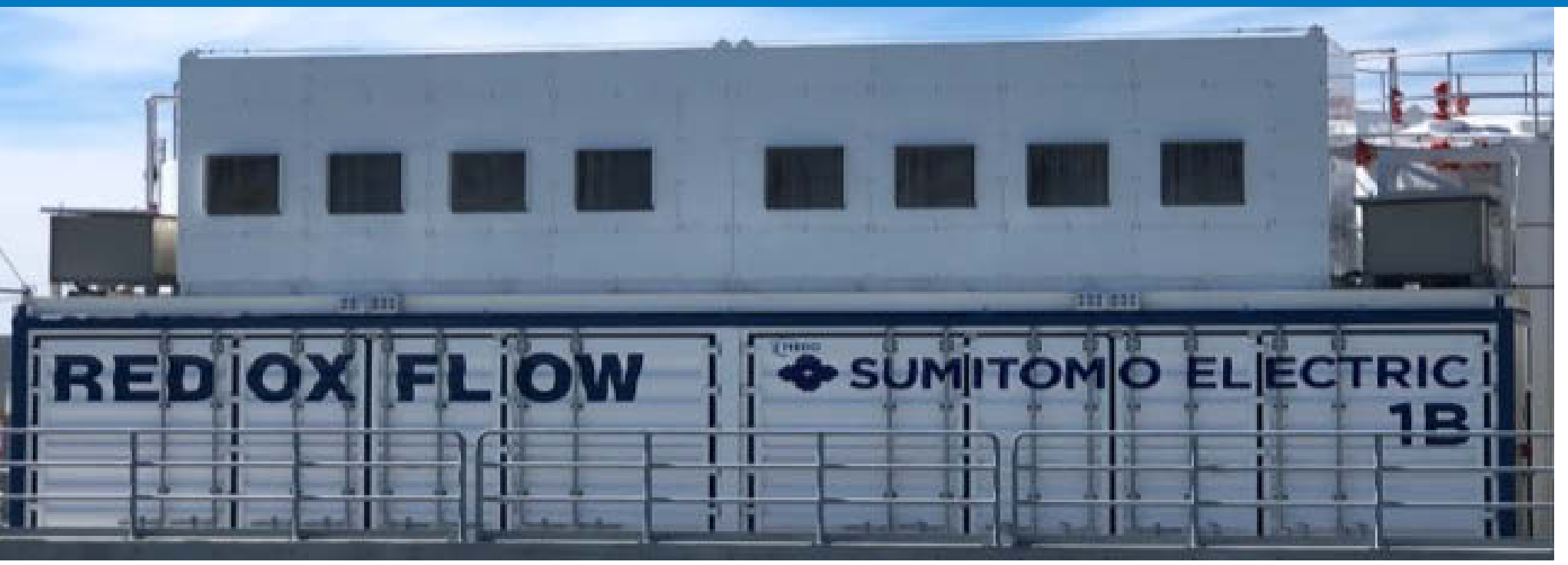

Description: NREL validated the technical and economic feasibility of an emerging vanadium flow battery technology through loss modeling, characterization, and field test

Technology: High fidelity vanadium flow battery

Impact: Identified value streams through the application of utility-scale vanadium redox flow battery for local grid support use cases

Partners: Sumitomo and SDG\&E
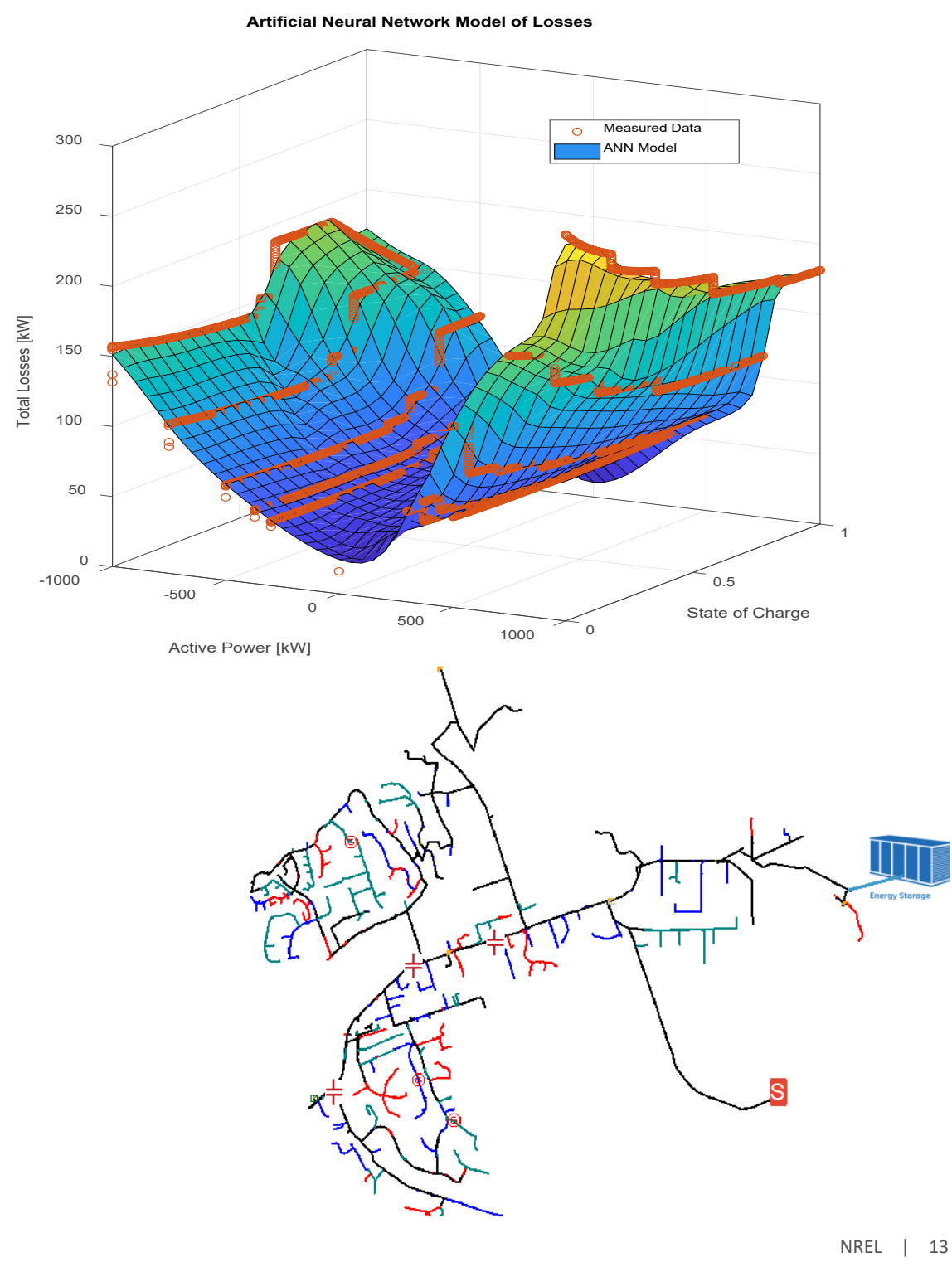


\section{Design Tradeoffs between Economics and Resilience}

Description: NREL used REopt to evaluate how long existing and proposed backup energy systems could sustain the critical load during an outage at an Army National Guard base. REopt evaluated thousands of random grid outage occurrences and durations and compared hours survived with diesel gensets vs. gensets augmented with PV and battery.

Technology: Solar, storage, diesel generation

Impact: PV and battery can provide savings and resilience. Site can achieve 4 extra days of resilience with no added cost.

Partner: Army National Guard

$\begin{array}{lrrrrrr} & \text { Generator } & \text { Solar PV } & \text { Storage } & \text { Lifecycle Cost } & & \text { Outage } \\ \text { 1. Base case } & 2.5 \mathrm{MW} & & & & \$ 20 \text { million } & 5 \text { days } \\ \text { 2. Lowest cost } & 2.5 \mathrm{MW} & 625 \mathrm{~kW} & 175 \mathrm{kWh} & \$ 19.5 \text { million } & 6 \text { days } \\ \text { 3. Proposed system } & 2.5 \mathrm{MW} & 2 \mathrm{MW} & 500 \mathrm{kWh} & \$ 20 \text { million } & 9 \text { days }\end{array}$

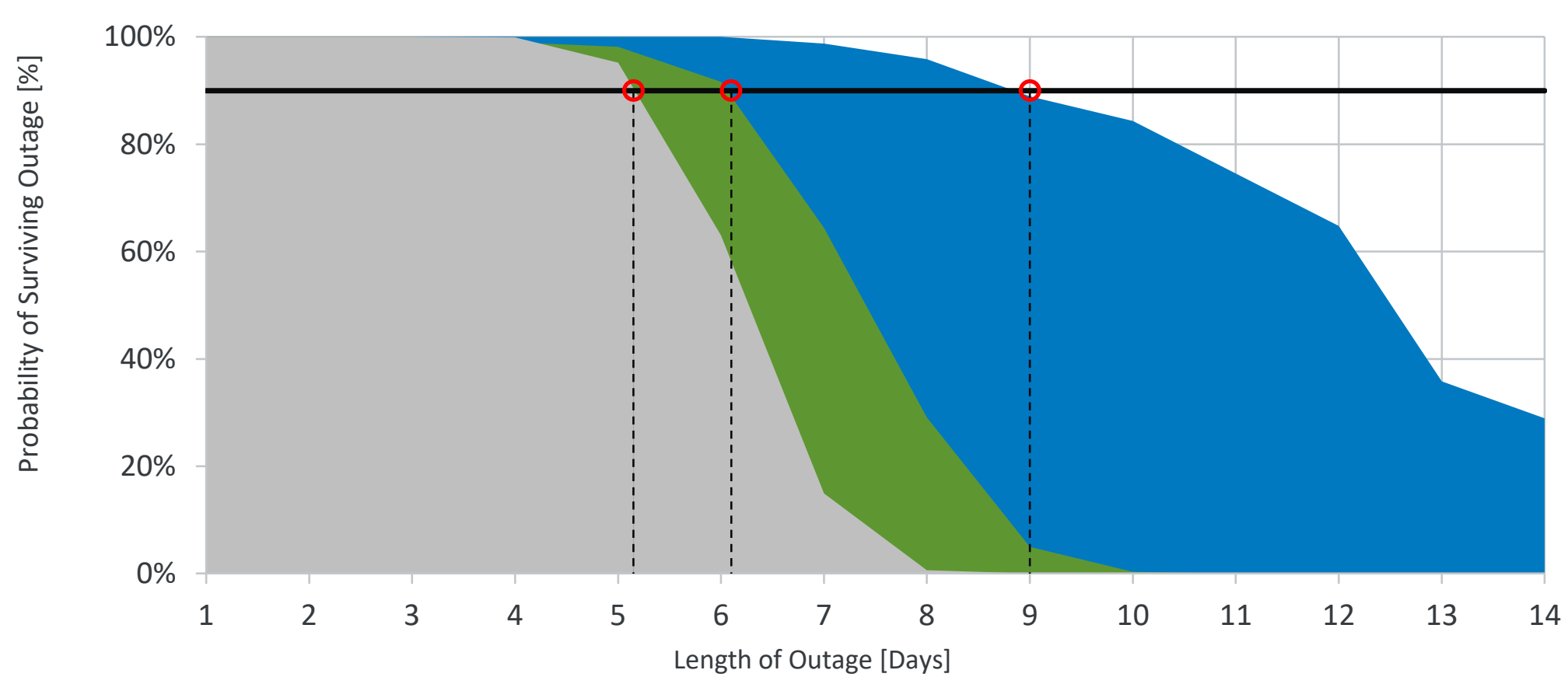




\section{Aligning Generation and Load With Storage and Demand Flexibility}

Description: NREL evaluated controllable load and storage options to improve customer economics of solar under post-net metering utility tariffs.

Technology: Solar, storage, buildings

Impact: Flexible loads increase the value of solar by aligning generation to load to maximize value.

Partner: DOE Solar
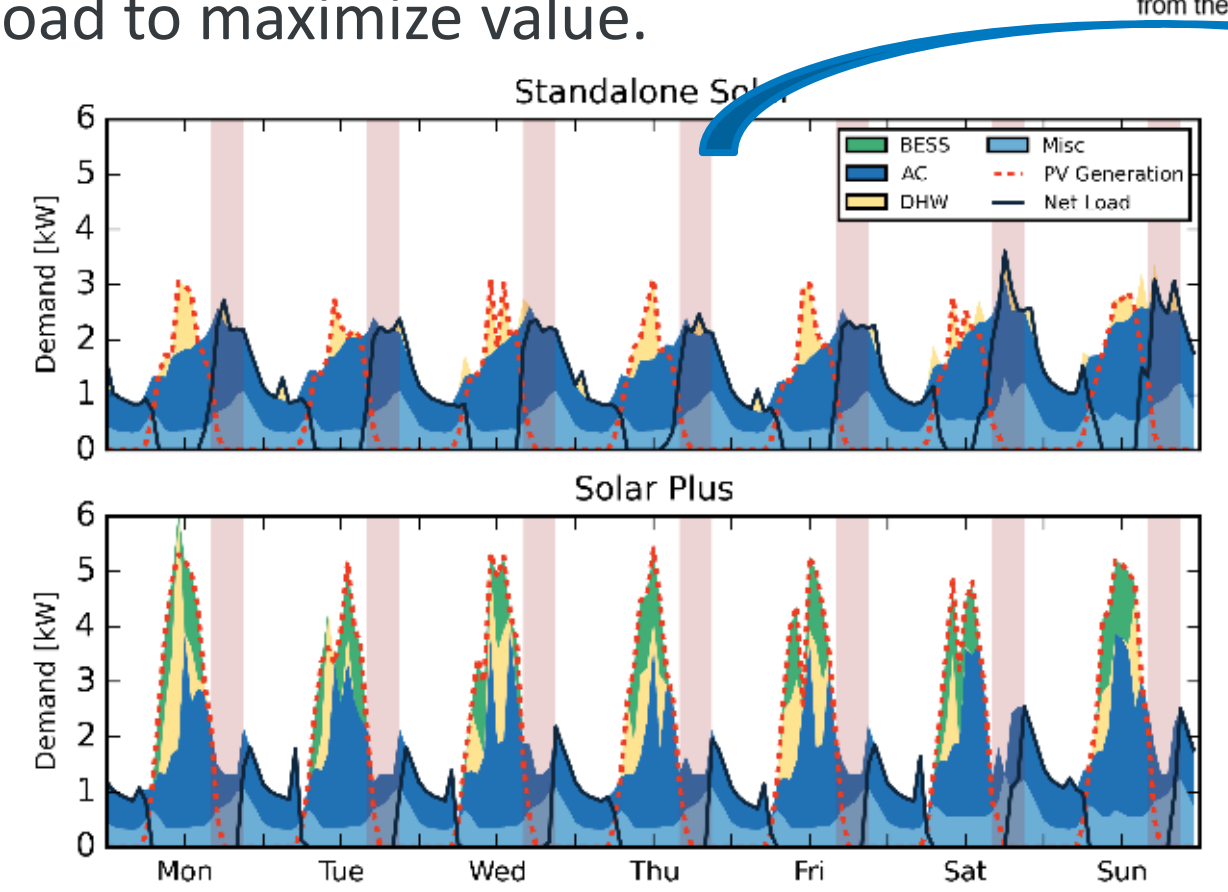

Solar PV

Solar PV energy may be self-consumed,

delivered to the grid, or stored in a batteny.

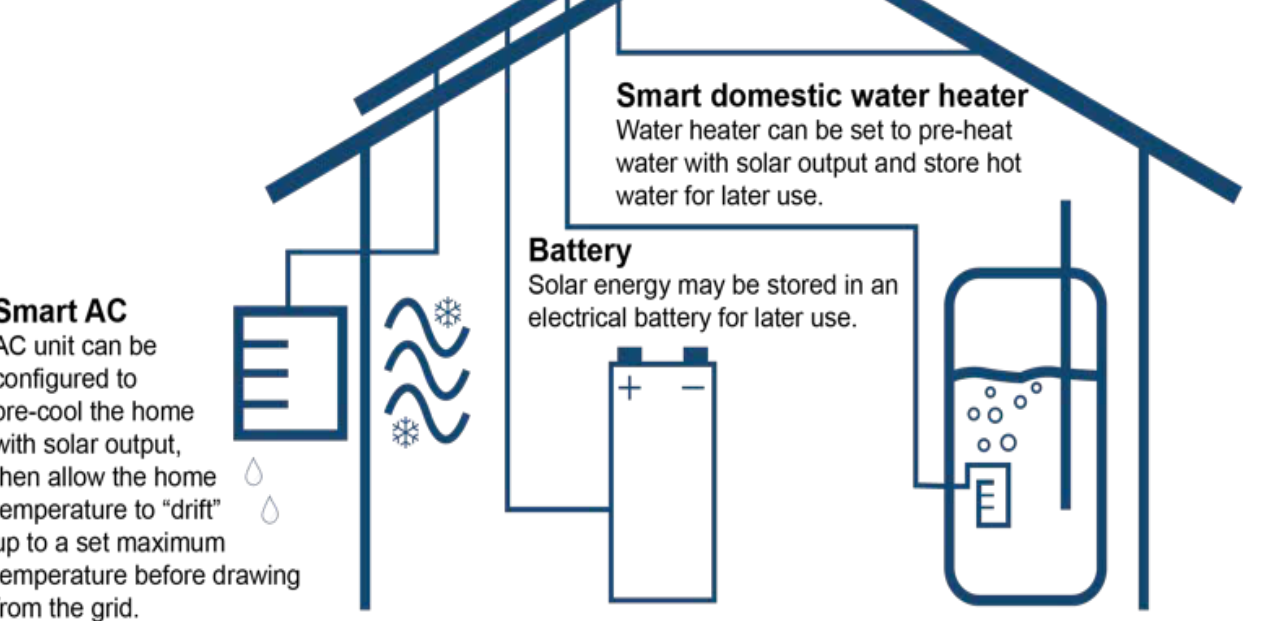
fom the grid.
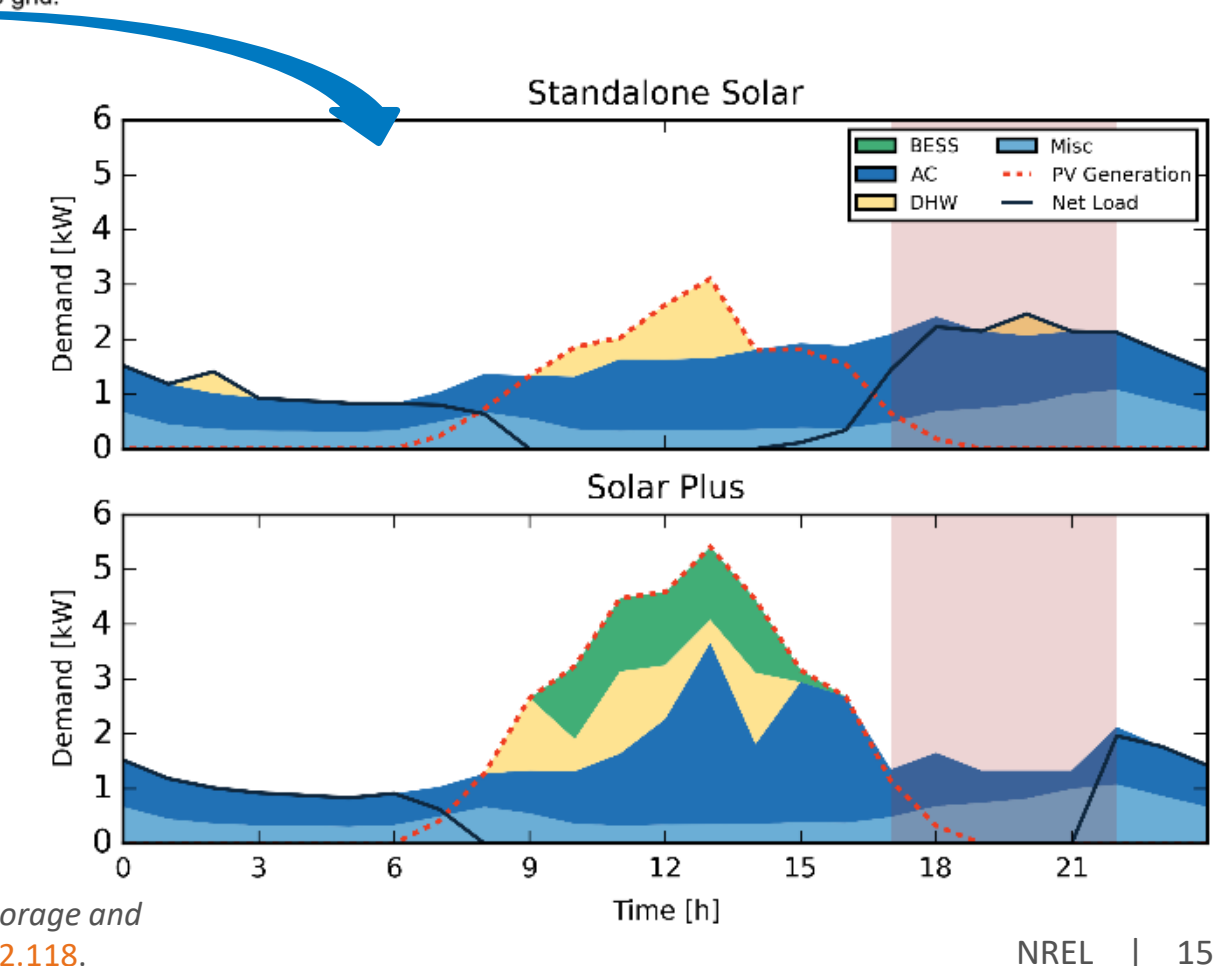


\section{Integrating EV Fleets With DER and Grid}

Description: NREL evaluated opportunities for synergistic integration and control of electrified transportation fleets with flexible buildings loads, RE, and stationary storage.

Technologies: Mobility, storage, buildings, solar, advanced system integration controls

Impact: Demonstrated optimal control of integrated $\mathrm{RE}$, building loads, storage, and EV system in laboratory testing. Integrated system provided increased value to the site owner.

Partners: Eaton (funding partner), Holy Cross Energy, SDG\&E, Duke Energy, UPS, EPRI

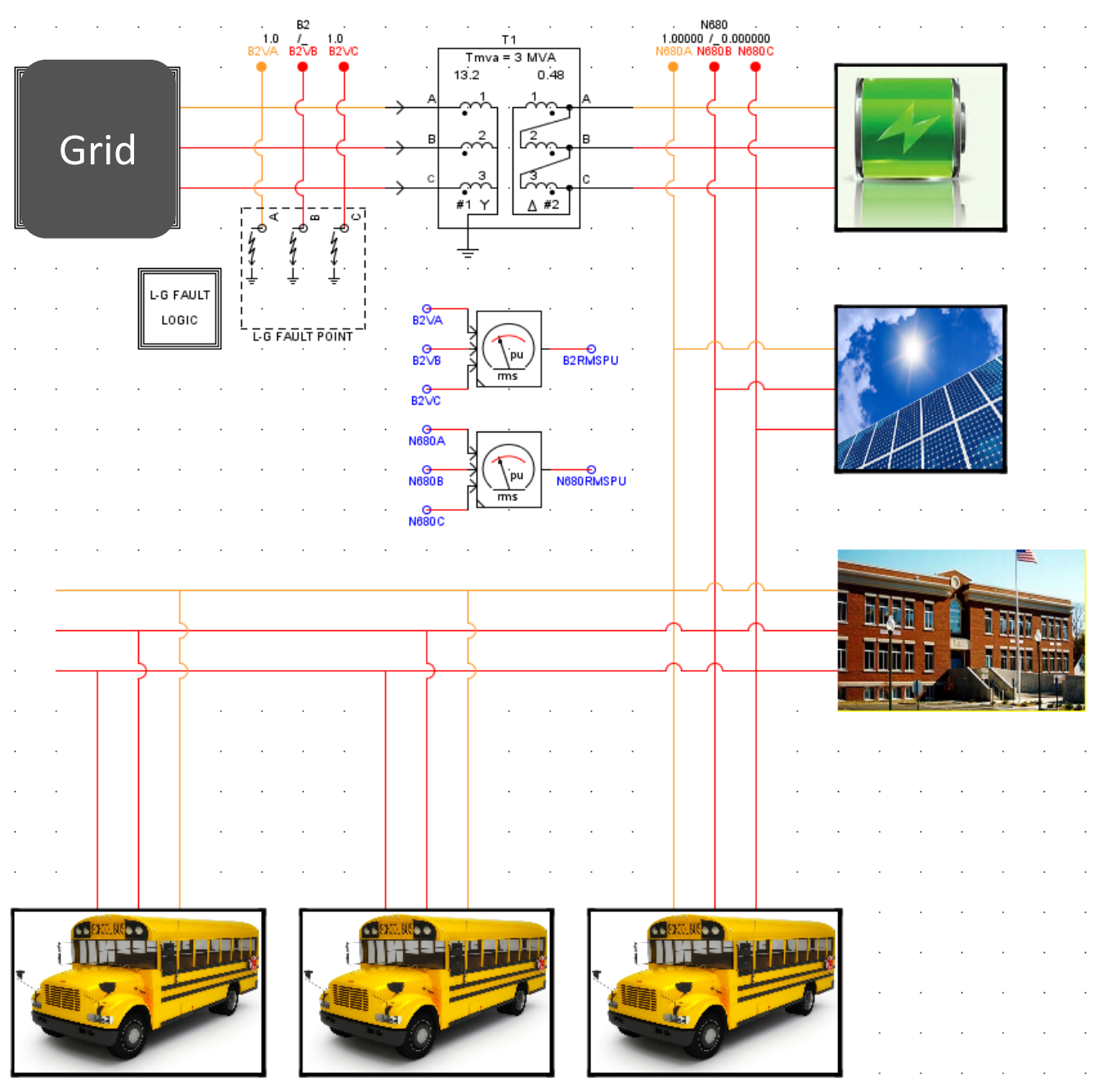




\title{
Additional Information
}

\author{
REopt Technical Description
}

REopt Development Team 


\section{REopt Model Technical Description}

\section{Mixed Integer Linear Program}

- Mathematical model written in the MOSEL programming language solved using commercial FICO Xpress solver

- Analysis typically requires significant site-specific and client-requested customizations

Solves energy balance at every time step for entire year (typically 15-minute or hourly interval)

- Load must be met from some combination of grid purchases, on-site generation, or discharge from storage

- Typically does not consider power flow or transient effects

- Has perfect prediction of upcoming weather and load

- Assumes all years in analysis horizon are the same (typically 25 years)

Technology modules based on empirical operating data

Finds optimal technology sizes (possibly 0) and optimal dispatch strategy subject to resource, operating, and goal constraints

- Objective function is to minimize life-cycle cost of energy

- Resulting life cycle cost is guaranteed optimal to within a known gap (typically $0.01 \%)$ subject to modeling assumptions

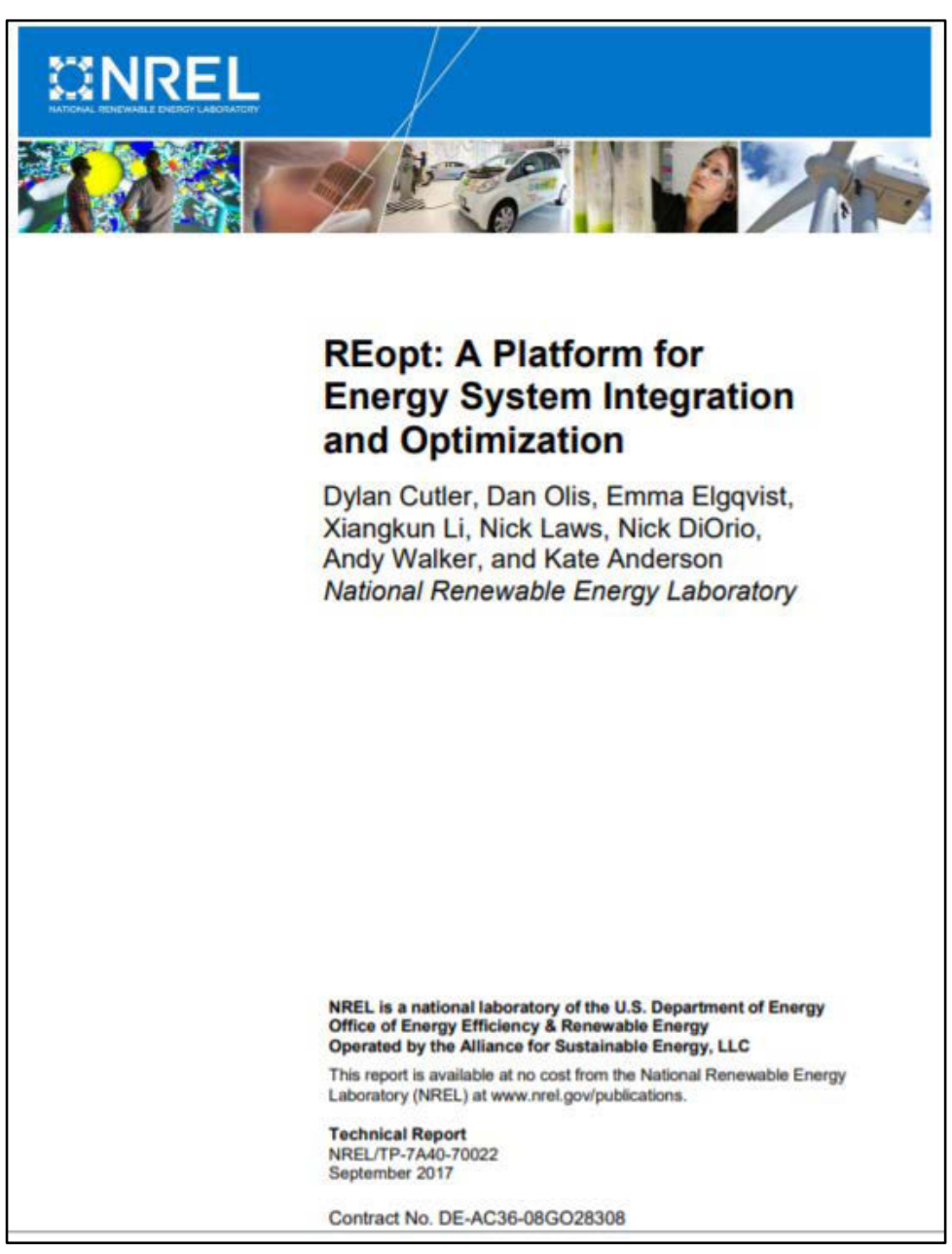




\section{REopt Team}

- $\quad$ Kate Anderson, Program Lead

- Dylan Cutler, Development \& Analysis

- Dan Olis, Validation \& Analysis

- Emma Elgqvist, Analysis

- Nick Laws, API Development \& Analysis

- $\quad$ Xiang Li, Development \& Analysis

- Kathleen Krah, Analysis

- $\quad$ Bill Becker, Development \& Analysis

- Andy Walker, Team Advisor
- Sakshi Mishra, Development \& Analysis

- Josiah Pohl, API Development \& Analysis

- Sean Ericson, Analysis

- Linda Parkhill, Validation and User Support

- Sam Chakrabarti, Development

- Rob Eger, UI Development

- Nick Muerdter, UI Development

- $\quad$ Andrew Jeffery, UI Development

- Ted Kwasnik, API Development

Contact: Kate Anderson Kate.Anderson@nrel.gov REopt@nrel.gov 


\section{(ㄱ) REOPt Rerewable Enegy}

REopt website (analysis services and case studies): reopt.nrel.gov

Tool feedback and questions: reopt@nrel.gov

\section{www.nrel.gov}

NREL/PR-7A40-76700

This work was authored by the National Renewable Energy Laboratory, operated by Alliance for Sustainable Energy, LLC, for the U.S. Department of Energy (DOE) under Contract No. DE-AC36-08GO28308. Funding provided by the U.S. Department of Energy Office of Energy Efficiency and Renewable Energy Federal Energy Management Program. The views expressed in the article do not necessarily represent the views of the DOE or the U.S. Government. The U.S. Government retains and the publisher, by accepting the article for publication, acknowledges that the U.S. Government retains a nonexclusive, paid-up, irrevocable, worldwide license to publish or reproduce the published form of this work, or allow others to do so, for U.S. Government purposes. 


\section{More REopt Projects}

Storage Sizing and Operation

Resilience and Microgrids

Integration of Flexible Loads

Electric Vehicles

Portfolio Optimization 


\section{Market Participation Strategy for SDG\&E Utility Storage}

Description: NREL optimized the dispatch of a battery on a San Diego Gas \& Electric (SDG\&E) feeder with high-PV penetration across multiple value streams (locational marginal price [LMP] arbitrage, frequency regulation, grid support functions).

Technology: Li-ion battery

Impact: Informed battery market participation strategy to maximize value for SDG\&E

Partners: SDG\&E

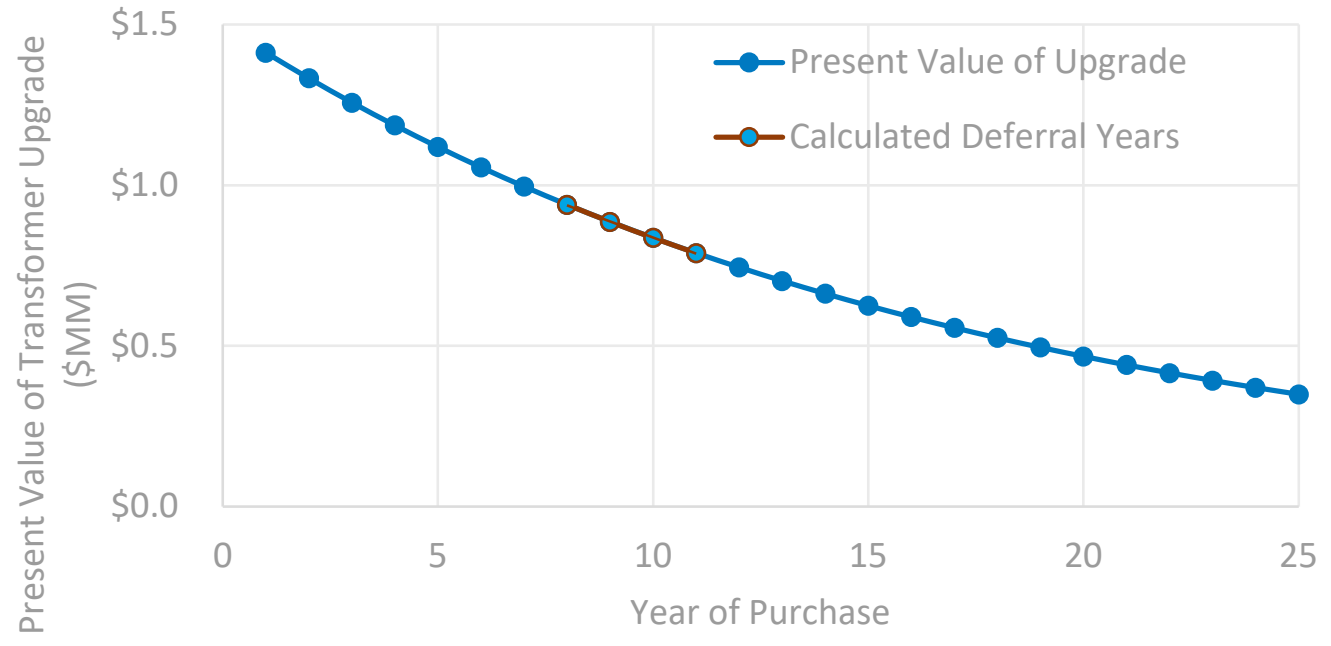

NREL assessed the value the battery provided by enabling deferral of a transformer upgrade through peak shaving on the feeder
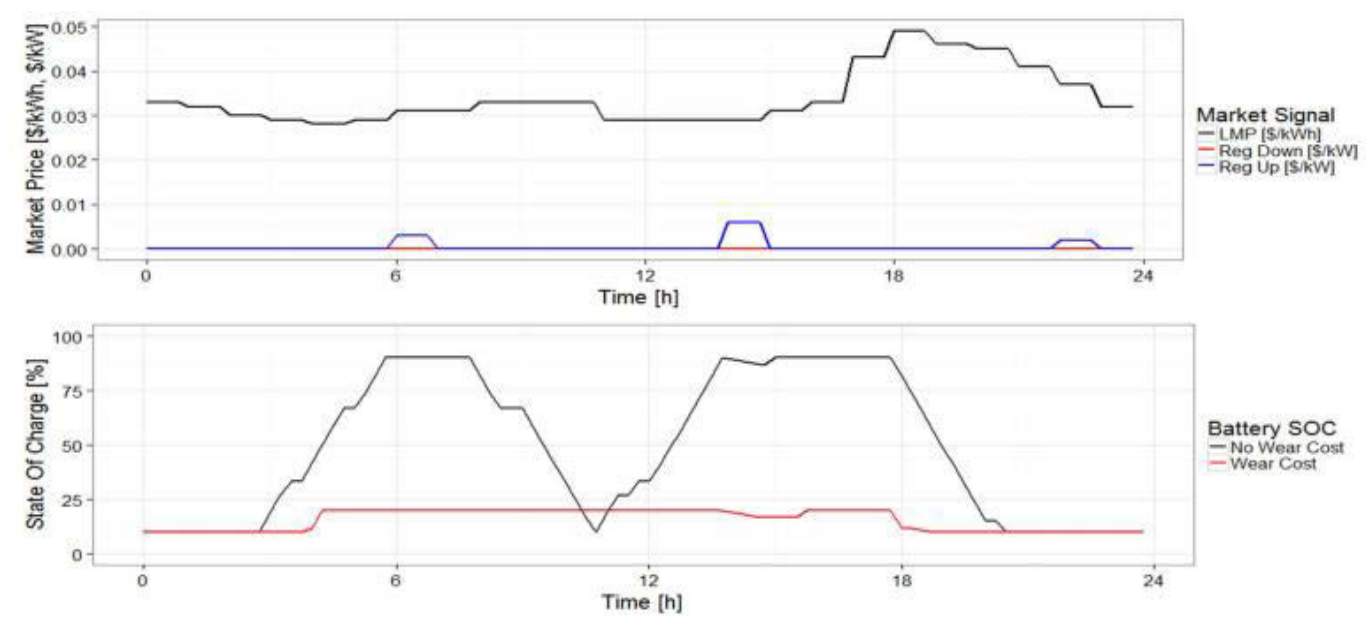

Battery market participation strategy: Incorporating degradation into the model changes optimal wholesale market dispatch
Murali Baggu et al. Coordinated Optimization of Multiservice Dispatch for Energy Storage Systems with Degradation Model for Utility Applications. Piscataway, NJ: IEEE Transactions on Sustainable Energy. April 2019. https://doi.org/10.1109/TSTE.2018.2853673. 


\section{PV+Battery Dispatch for Municipal Utility in PJM}

Description: NREL used REopt to determine the optimal dispatch to mitigate coincident peak demand charges.

Technology: Natural gas reciprocating engines and battery storage

Impact: Identified potential for \$171 million in savings, including:

- 92.8-GWh reduction in annual market purchases (\$79.6 MM)

- $\quad$ 53.6-MW reduction in $1 \mathrm{CP}$ demand charges (\$39.1 MM)

- 61.2-MW reduction in 5 CP demand charges (\$51.8 MM)

Partner: Utility in PJM

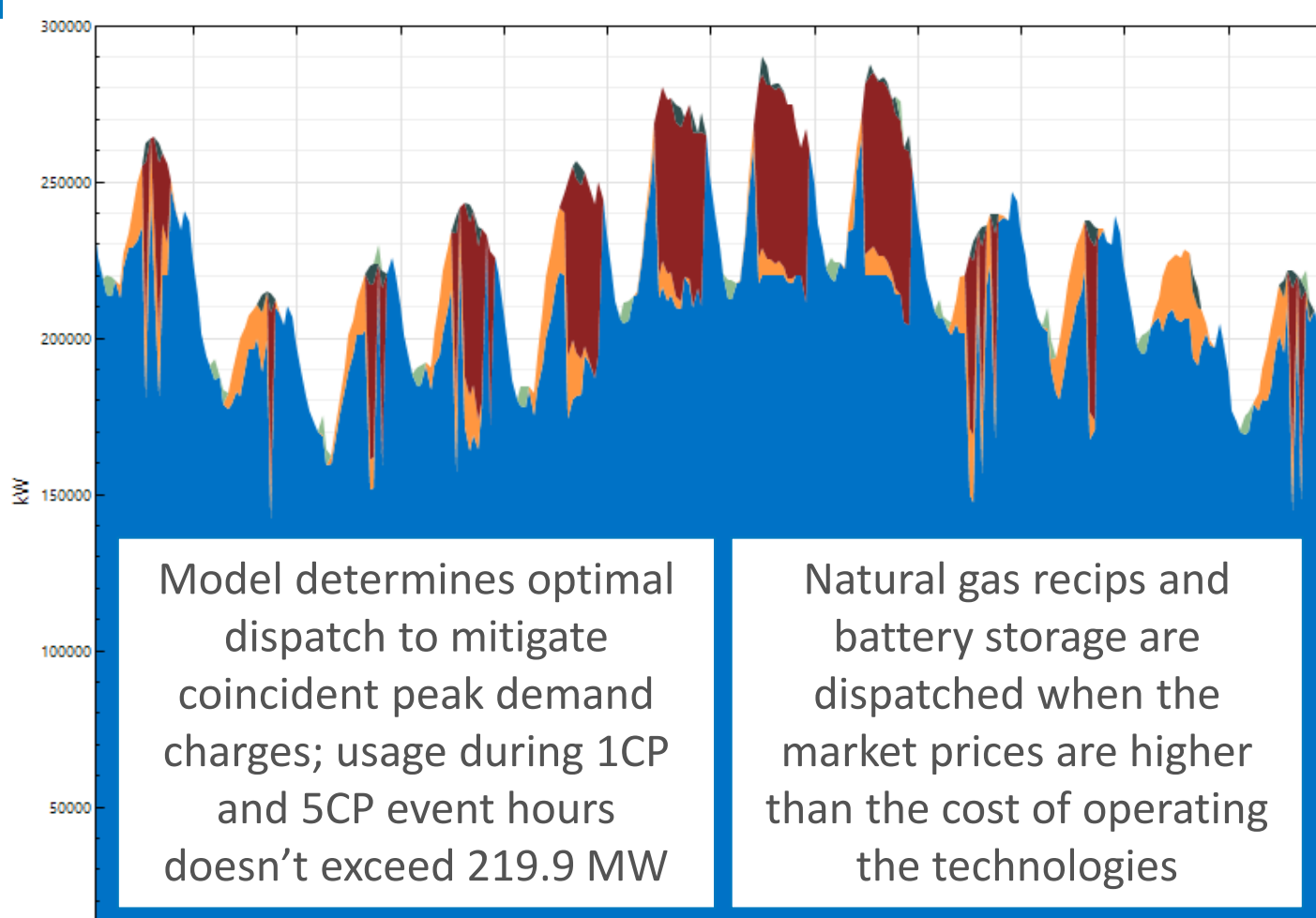

-Grid to Load (kW) -PV to Load (kW) -Recips to Load (kW) -Grid to Storage (kW)

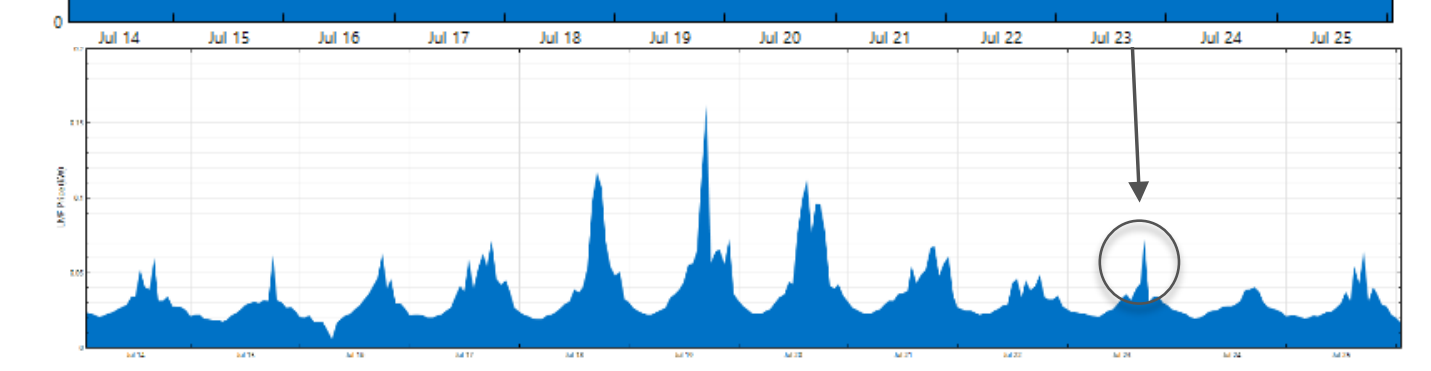




\section{Battery Economics}

Description: NREL evaluated the economic impact of health-conscious battery controls that consider the trade-off between operational value and degradation cost.

\section{Technology: Storage}

Impact: Evaluated battery sizing and operational decisions considering degradation impacts. Findings are being validated through battery pack testing at NREL and will then be integrated into Eaton controls approaches.

Partner: Eaton

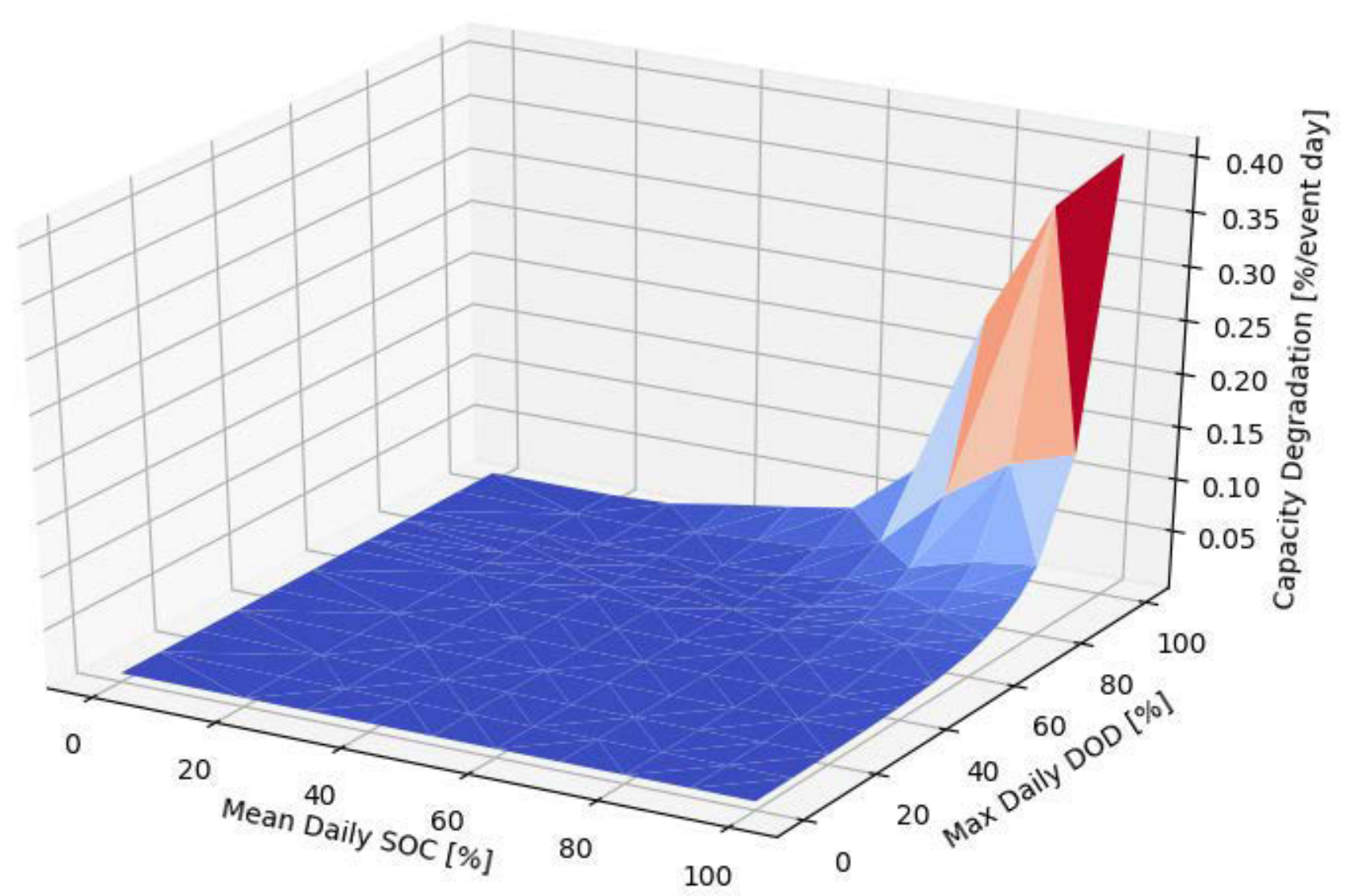

Degradation increases with maximum depth of discharge and high mean state of charge 


\section{Evaluating Centralized vs. De-centralized Microgrid Options for Military Installations}

Description: NREL performed an integrated microgrid feasibility analysis for three U.S. military installations to support U.S. Army energy resilience requirements.

Technologies: Solar PV, battery storage, combined heat and power (CHP), chillers (adsorption and centrifugal), hot- and cold-water thermal storage, microgrid components

Impact: Developed conceptual design and cost estimate for integrated microgrids to provide energy cost savings and resilience across the three international U.S. military installations.

- Addressed electric vs. heat and resiliency vs. cost prioritization for CHP operation

- Resulted in successful RFP for optimized microgrid design.

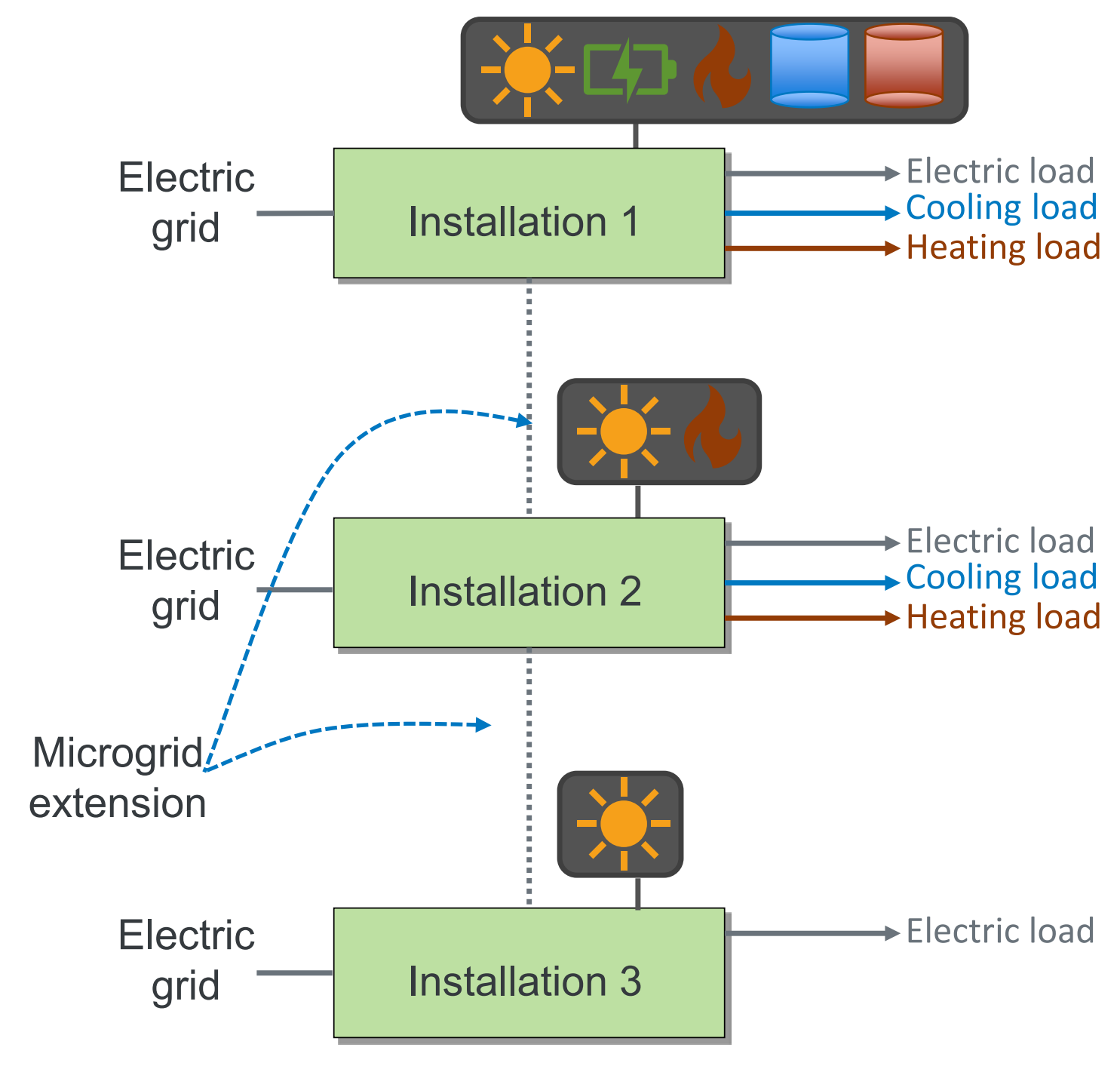

Partners: United States Army Garrison Italy 


\section{Microgrids for Rural Energy Access In Africa}

Description: NREL used REopt to optimize microgrid designs for systems across subSaharan Africa, analyzing the impact of cost trends, technology choices, business models, and regulatory structures to identify least-cost pathways to rural electrification

Technology: PV, li-ion and lead-acid batteries, diesel generation

Impact: Informed rural microgrid design decisions and government policies around energy access goals

Partners: USAID, AMDA, individual microgrid developers, national governments in subSaharan Africa
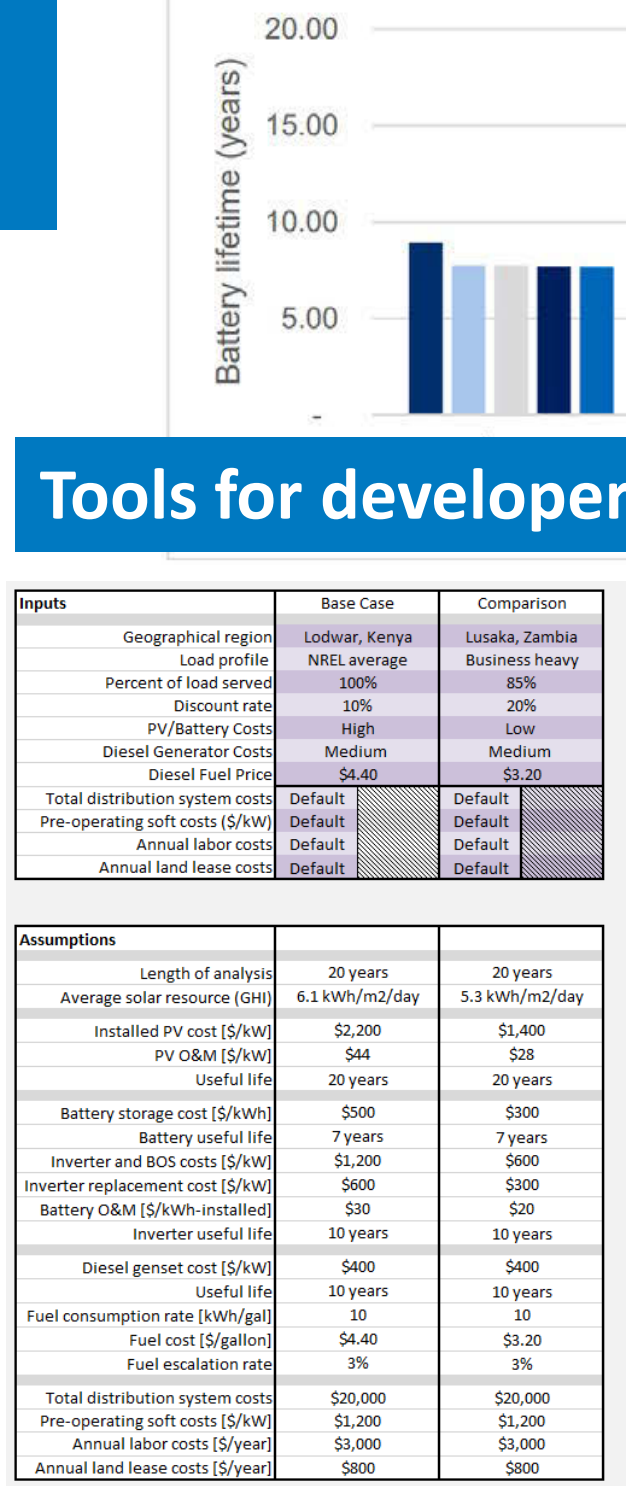

- Fuel - O\&M (excluding labor) DER CAPEX - Diesel CAPEX - Pre-operation soft costs - Distribution network Eight Fans Four Fans =Evaporative Cooler = NoSystem
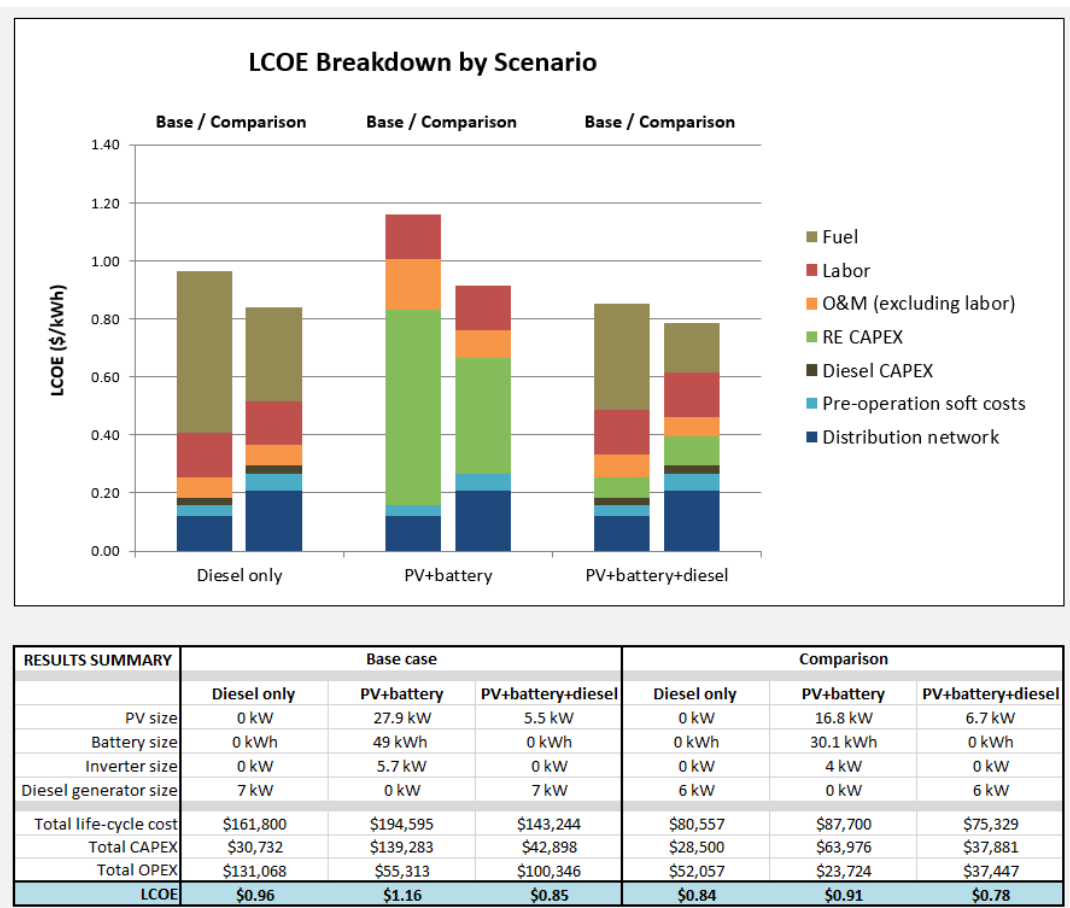


\section{Market Revenues for Backup Generators}

Description: NREL evaluated the value backup generators can provide when used for gridconnected economic dispatch. NREL considered potential revenues from tariff switching, peak shaving, energy selfgeneration, coincident peak reduction, wholesale real-time pricing, spinning reserve markets, and emergency standby programs.

Technology: Natural gas and diesel generators

Impact: The overall cost of back-up generation can be lowered, but opportunities vary across the United States, depending on markets.

Partner: Enchanted Rock

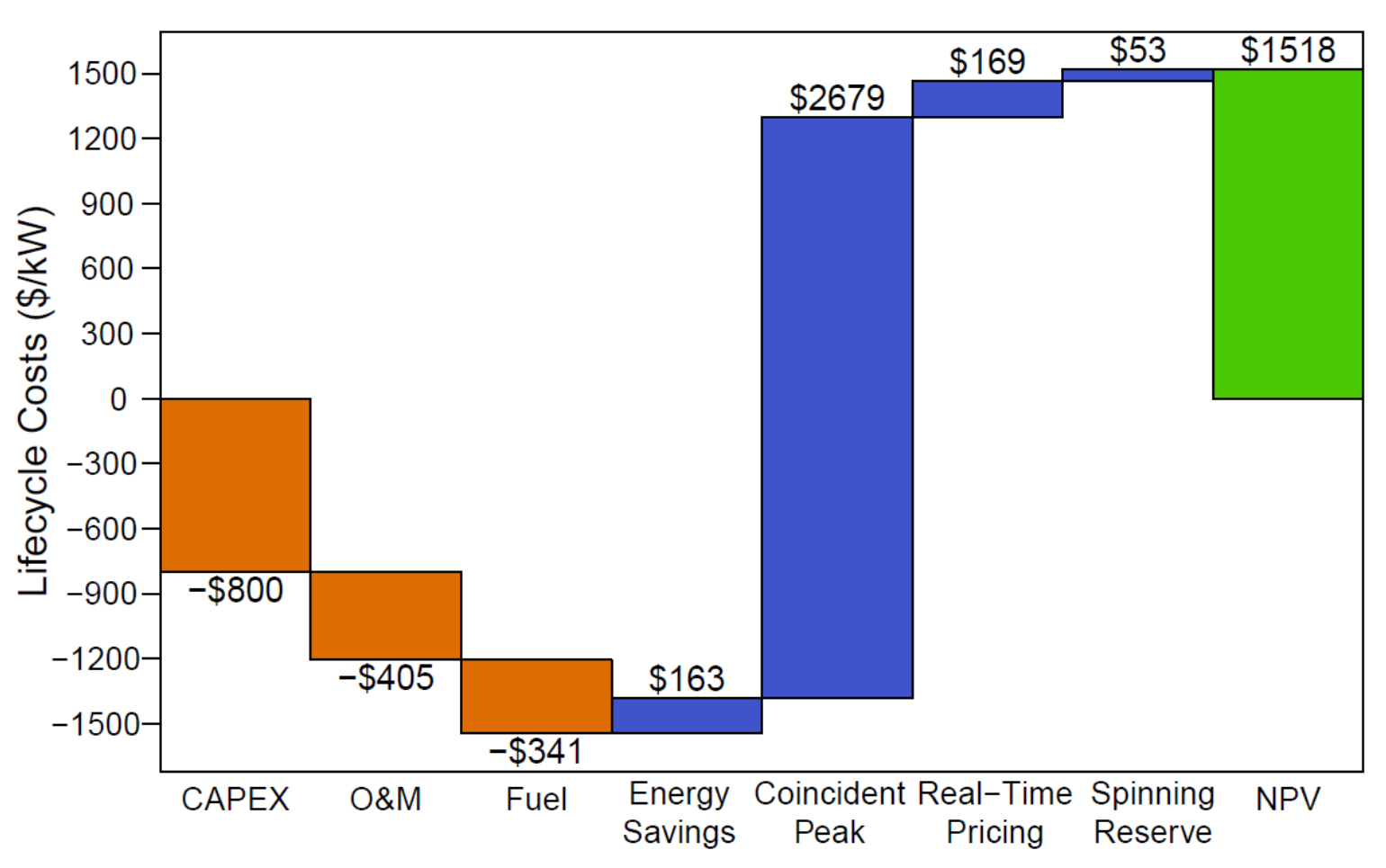

Life cycle costs and revenues $(\$ / \mathrm{kW})$ for diesel generator providing grid services in Camden, NJ

\begin{tabular}{|c|c|c|c|c|c|c|}
\hline \multirow{2}{*}{$\begin{array}{l}\text { Generator Type } \\
\text { Region }\end{array}$} & \multicolumn{3}{|c|}{ Diesel } & \multicolumn{3}{|c|}{ Natural Gas } \\
\hline & TX & $\mathrm{FL}$ & NJ & TX & $\mathrm{FL}$ & NJ \\
\hline CAPEX + O\&M (\$/kW) & \multicolumn{3}{|c|}{$-\$ 1,205$} & \multicolumn{3}{|c|}{$-\$ 1,405$} \\
\hline Revenues/savings (\$\$W) & $\$ 968$ & $\$ 1,380$ & $\$ 3,064$ & $\$ 1,091$ & $\$ 1,380$ & $\$ 3,153$ \\
\hline Fuel cost for (\$/kW) & $-\$ 187$ & $\$ 0$ & $-\$ 341$ & $-\$ 199$ & $\$ 0$ & $-\$ 272$ \\
\hline NPV (\$/kW) & $-\$ 425$ & $\$ 175$ & $\$ 1,518$ & $-\$ 513$ & $-\$ 25$ & $\$ 1,476$ \\
\hline
\end{tabular}

Net present values by region and by fuel type 


\section{Water Treatment} and Storage

Description: NREL optimized an offgrid water treatment and storage system on Navajo lands.

Technologies: PV, diesel generator, storage, water treatment and storage

Impact: Identified opportunities to reduce battery size and fuel use by flexing pumping loads and using storage inherent in water tank.

Partner: U.S. Bureau of Reclamation

NREL. “REopt Modeling Informs Design of Off-Grid Water System Under Study for Navajo Nation." Accessed April 22, 2020.
Added

components

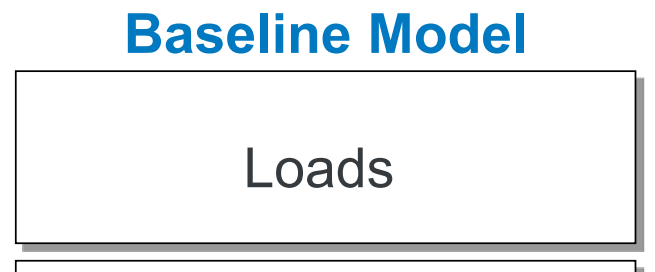

Power Options and

Characteristics
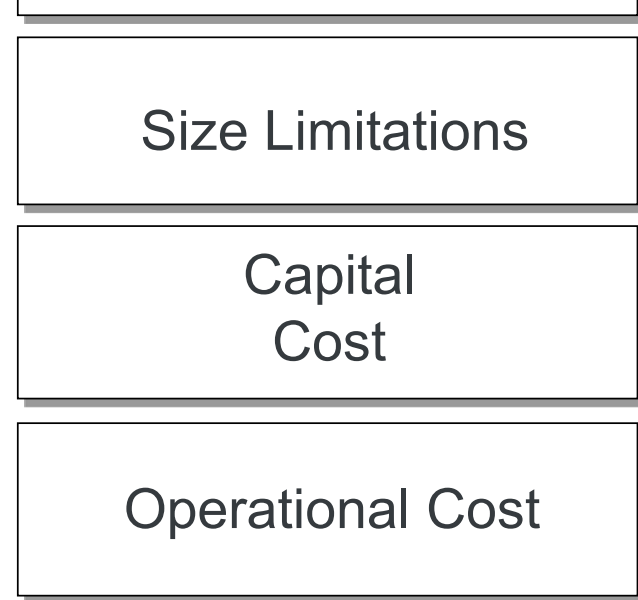

\section{Optimized System}

Equipment size and operating requirements for each process component
+ Generator

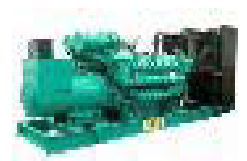

Battery

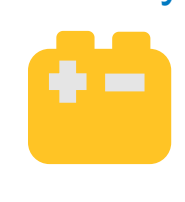

REopt Model

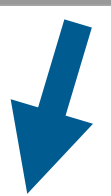

+ Water Treatmen

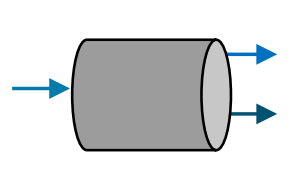

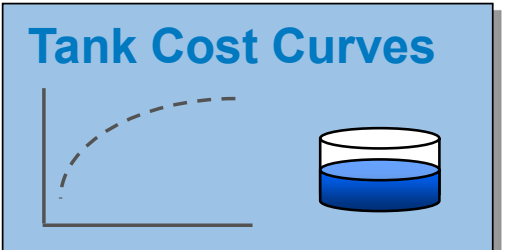

Pump Cost Curves

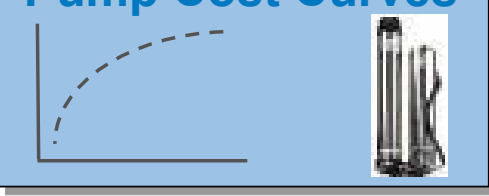

Water Treatment Unit Cost Curve

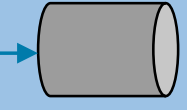

Water loads Pump and treatment power requirements
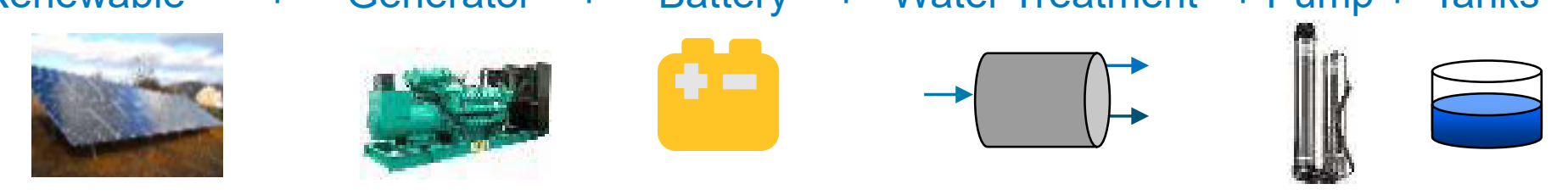


\section{Fast Charging Station Design}

Description: NREL explored solutions that can help make DC fast charging (DCFC) more affordable for EV drivers in the United States:

- Solar PV and/or energy storage (batteries)

- Co-locating DCFC with a commercial building

Technologies: DCFC, solar, battery storage

Impact: Found $11 \%-40 \%$ of sites can reduce lifetime electricity cost by installing technologies. Co-location often economically preferable but relative savings diminish as load increases.

Partners: DOE Vehicle Technologies Office
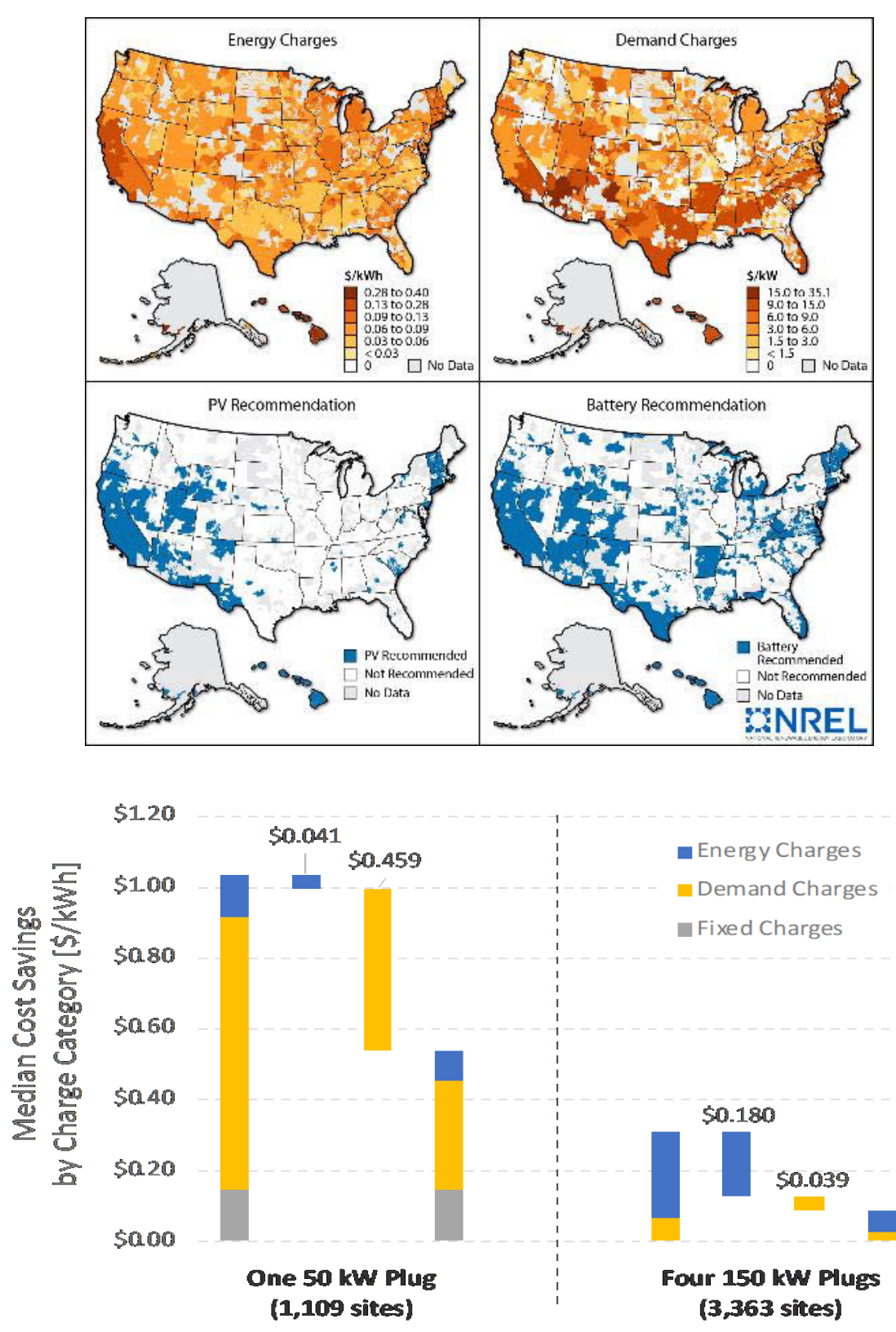


\section{Impact of EV Workplace}

\section{Charging in Minnesota}

Description: NREL used REopt to evaluate the economics of workplace EV charging. NREL's EVI-Pro database used to generate static and flexible EV load profiles.

Technology: EVs, PV, storage

Impact: Found savings from adding PV and storage to EV charging infrastructure and/or flexibility in EV charging times.

Partner: City of Minneapolis

\section{(0) REopt

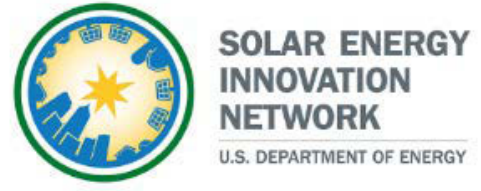

Load Data for 6 EV Chargers - First Week of January
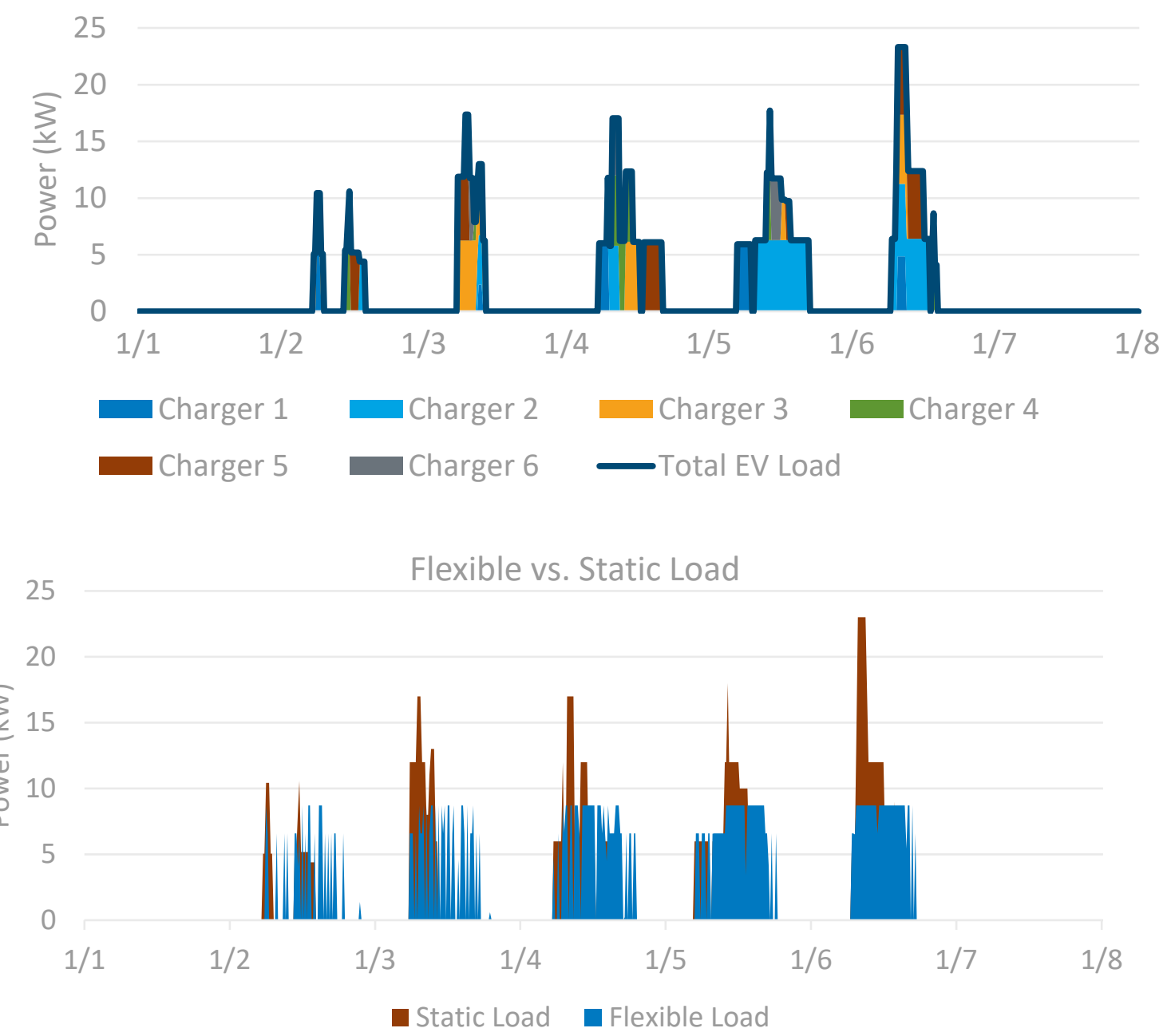


\section{National Economic Analysis of Behind-the-Meter Storage}

Description: Analyzed behind-the-meter solar and storage economics across 16 climate zones, 16 building types, 80 utility rate tariffs, and varying technology price points

\section{Technology: PV, storage}

Impact: Identified critical factors in the cost-effectiveness of solar+storage in commercial buildings

Partner: DOE Solar Energy Technologies

Office

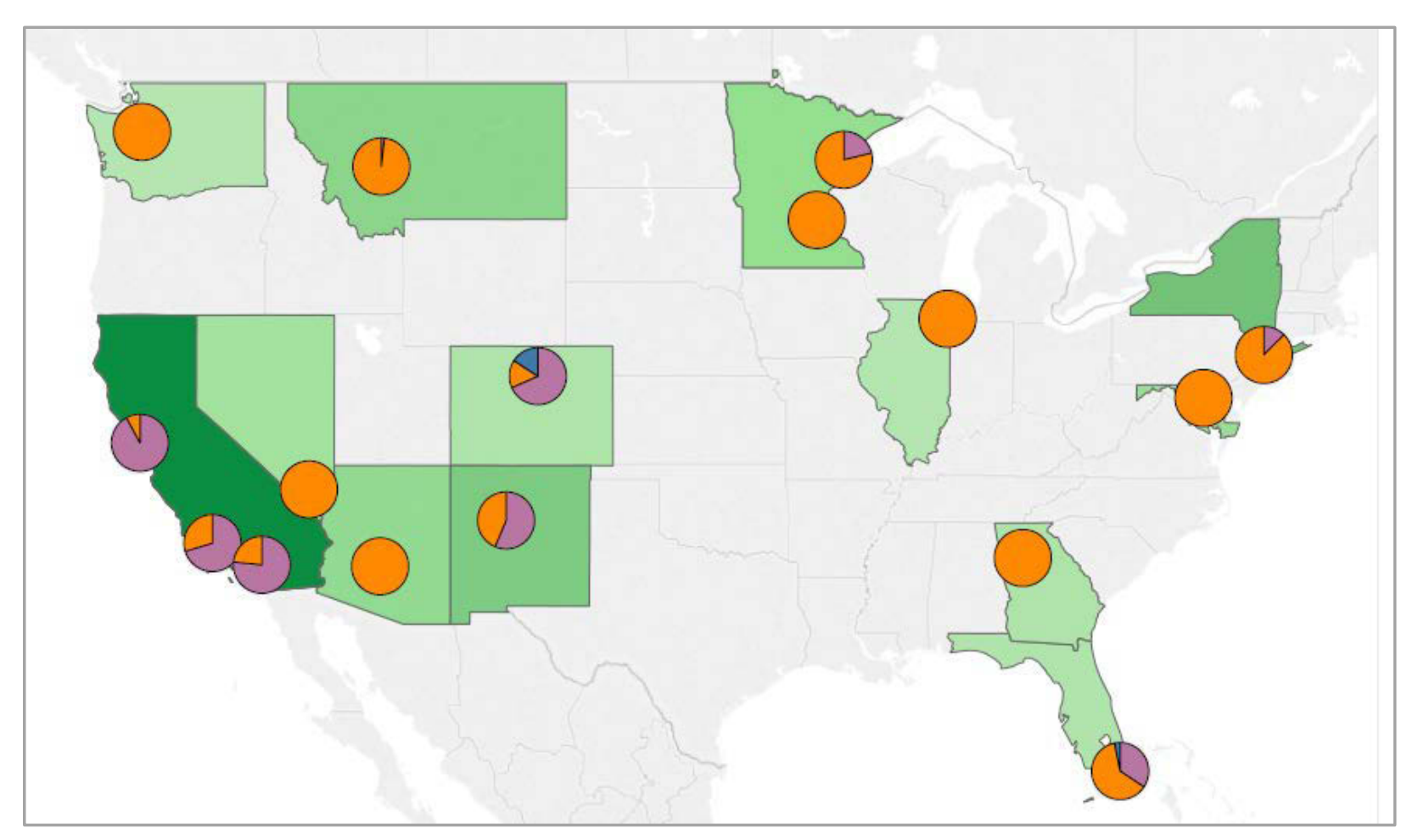

Average Expected \% Savings Across All Cases Modeled $0 \%$

Percent of Cases Modeled with Resulting Technology Combination

$$
\square \text { Solar Only }
$$




\section{Deploying Cost-Effective Efficiency, Renewable Energy, and Storage}

Description: NREL is working with the Army Office of Energy Initiatives to evaluate RE and storage projects across 100 Army bases. NREL is prioritizing technically and economically feasible projects and assisting in project development.

Technology: PV, wind, CHP, biomass, natural gas, storage, microgrids

Impact: Identifying cost-effective RE, storage, and microgrid projects to reduce Army energy cost and increase installation resilience

Partners: U.S. Army Office of Energy Initiatives

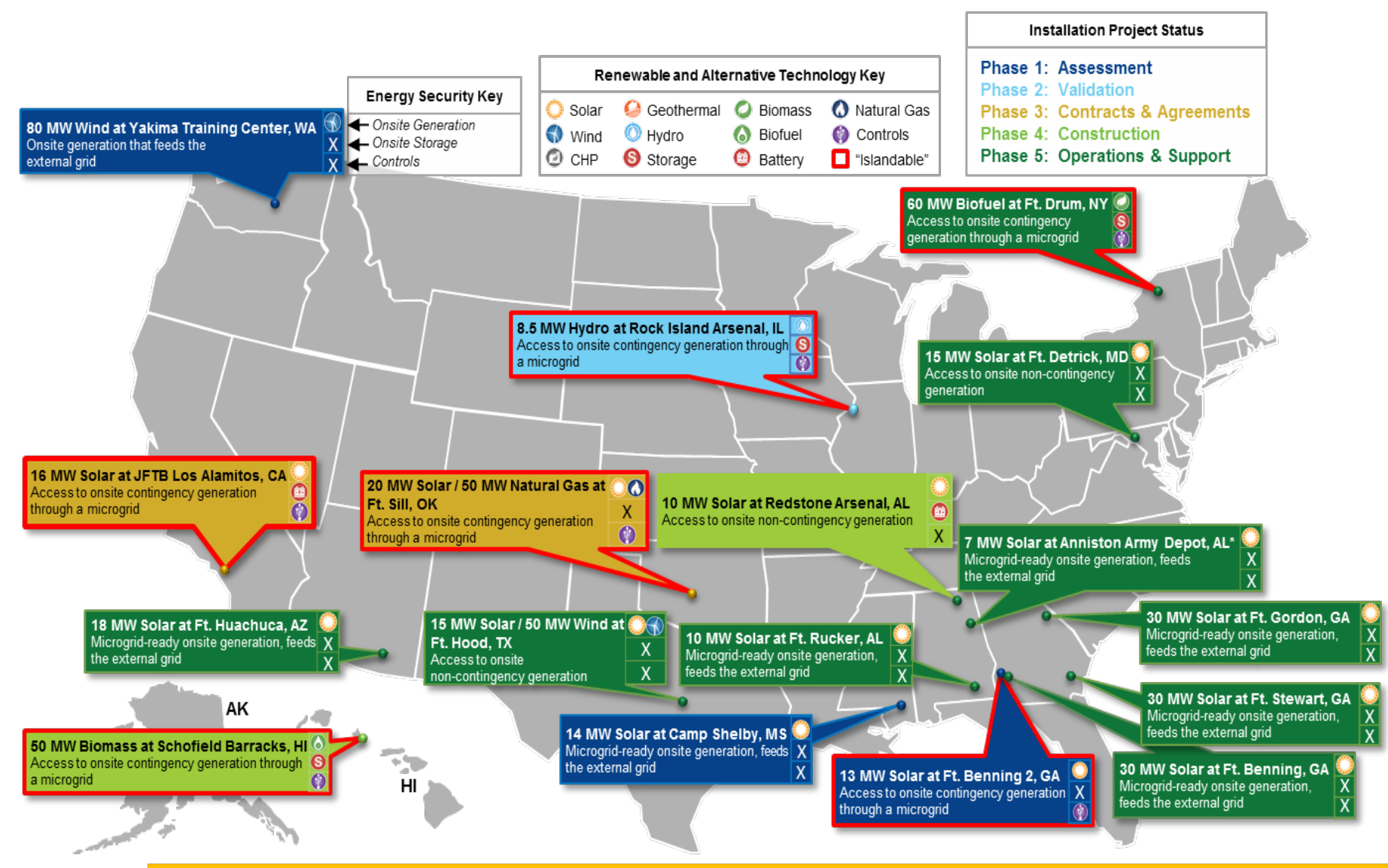

Increasing Energy Security and Resiliency Across Army Installations 


\section{Identifying and Prioritizing Projects Across a Portfolio}

Description: NREL evaluated 700 sites for Time Warner Cable to identify and prioritize technically and economically feasible RE and storage projects and estimate the cost of meeting renewable energy goals.

Technology: PV, wind, ground-source heat pump, storage

Impact: Identified cost-effective RE and microgrid projects to meet Time Warner Cable energy goals for reduced energy use, reduced energy cost, and increased resilience.

Partners: Time Warner Cable, Inc.
Economically viable PV projects across TWC portfolio

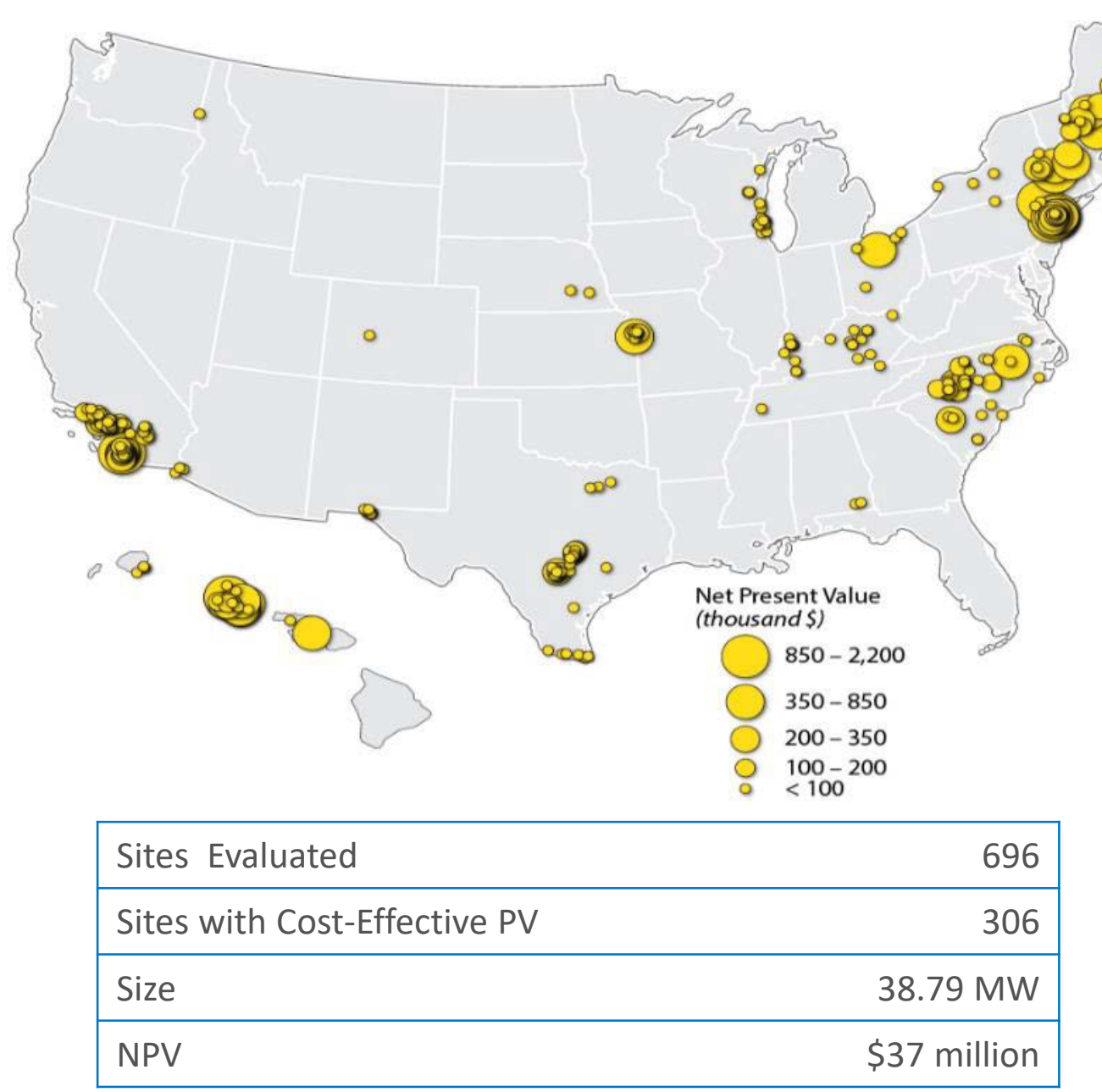

